\title{
Smooth Adaptive Finite Time Guidance Law with Impact Angle Constraints
}

\author{
Bin Zhao and Jun Zhou \\ Institute of Precision Guidance and Control, Northwestern Polytechnical University, Xian 710072, China \\ Correspondence should be addressed to Bin Zhao; binzhao@nwpu.edu.cn
}

Received 28 March 2016; Accepted 23 June 2016

Academic Editor: Hikmat Asadov

Copyright ( 2016 B. Zhao and J. Zhou. This is an open access article distributed under the Creative Commons Attribution License, which permits unrestricted use, distribution, and reproduction in any medium, provided the original work is properly cited.

\begin{abstract}
A smooth guidance law for intercepting a maneuvering target with impact angle constraints is documented based on the nonsingular fast terminal sliding mode control scheme and adaptive control scheme. Different from the traditional adaptive law which is used to estimate the unknown upper bound of the target acceleration, a new adaptive law is proposed to estimate the square of target acceleration bound, which avoids the use of the nonsmooth signum function and therefore ensures the smoothness of the guidance law. The finite time convergence of the guidance system is guaranteed based on the Lyapunov method and the finite time theory. Simulation results indicate that under the proposed guidance law the missile can intercept the target with a better accuracy at a desired impact angle in a shorter time with a completely smooth guidance command compared with the existing adaptive fast terminal sliding mode guidance laws, which shows the superiority of this method.
\end{abstract}

\section{Introduction}

In the traditional sense, the main objective of guided missile is to intercept targets with minimum miss distance [1]. In order to further enhance the missile's effectiveness against target, striking the target at a desired intercept angle would be required. Therefore, impact angle guidance law (IAGL) has become an attractive research topic recently.

Due to their high efficiency and easy implementation, the proportional navigation guidance law (PNGL) and its variants [2-5] have been widely used as the homing guidance law while intercepting nonmaneuvering or weekly maneuvering target. Taken for granted, they are also used to intercept targets with impact angle constraints. Kim et al. [6] proposed a modified PNGL which includes a supplementary time-varying bias to compensate for target acceleration as well as achieve a desired attitude angle at impact. Similarly, Erer and Merttopçuoglu [7] stated an impact angle guidance law biased pure proportional navigation. An alternative way of constructing IAGL is to vary the PN gains over time. However, as discussed by $[8,9]$, these guidance laws can only deal with the stationary target or nonmaneuvering targets. When intercepting a target with maneuverability close to that of the missile, the performance of PNGL cannot be guaranteed [10].

Afterwards, the optimal controls (OC) [11-13], $H_{\infty}$ controls $\left(H_{\infty} \mathrm{C}\right)[14,15]$, and the sidling mode controls (SMC) [16-19] were exploited to construct IAGL. Reference [11] proposed impact angle guidance law for intercepting a nonmaneuvering target, which seems to be the first attempt to derive the IAGL using OC. In [12] another OC guidance law with interception angle control was derived for weekly maneuvering target. As discussed elsewhere [13], Schwarz inequality was employed to derive the OC guidance law. The above OC guidance laws are derived from the linearized engagement dynamics which leads to the degradation of their performance while the initial heading error is larger. In addition these guidance laws require the time-to-go $\left(t_{\mathrm{go}}\right)$ information which is usually a formidable challenge. Due to the strong robustness against disturbance, the $H_{\infty}$ control based IAGLs were proposed in $[14,15]$. However, the difficulty of finding the analytic solution to associated Hamilton-Jacobi partial differential inequality makes them unrealizable.

So far, the SMC has been widely used to design IAGLs because of its good robustness to external disturbance and model uncertainty. At the early stage, the linear sliding 
manifold [16] was employed to deal with the nonlinear interception problems. As described in $[17,18]$, this kind of sliding manifold can only concern the exponential stability during the sliding phase; as a result the interception accuracy is difficult to ensure. To overcome this disadvantage, the terminal sliding mode control (TSMC) [19, 20] with nonlinear sliding manifold was proposed and exploited to construct IAGLs $[1,21,22]$. To improve the convergence rate of TSMC when the system states are far from the origin, fast terminal sliding mode control (FTSMC) combining the TSMC and the SMC was given in [23], based on which the IAGLs were proposed in $[24,25]$; these IAGLs can not only assure the convergence rate away from the origin but also acquire the properties of finite time convergence. However, the expressions of the above guidance laws contain negative exponential term of the system state, which leads to the singularity problem when error being controlled becomes very small; it is almost a disaster for the attitude control system to track. To this end, the nonsingular terminal sliding mode control scheme (NTSMC) and nonsingular fast terminal sliding mode control scheme (NFTSMC) were proposed in [26-28] and had been successfully used to design IAGLs [29-34]. Within the above articles, the target acceleration is considered as the unknown model disturbance. From the point of view of control theory, to make sure that the sliding mode possesses invariance property to external disturbance, usually the signum term is employed with its switching gain larger than the disturbance bound. As a result, almost all of the aforementioned IAGLs have to face one or several of the following limitations.

(1) Some guidance laws are noncontinuous due to the usage of the signum function $[1,18,24,25,29,31-$ 33 , which would pose great challenges to the system stability and deduce the control quality of the system.

(2) To determine the switching gain of the signum function, the information of the target maneuvering is required $[1,18,21,22,24,26,28,29,32,33]$, such as the target acceleration bound, which is an unreality condition for noncooperative target. Another idea is to ignore the target acceleration [22], which is only suitable for the scenario that the maneuverability of the target (such as tanks or large ships) is far weaker than the missile.

(3) To obtain the target information, different adaptive methods $[29,32]$ for estimating the target acceleration bound are integrated with IAGLs. However, these guidance laws still contain discontinuous term about the estimated value, which also brings the problem of nonsmoothness and chattering.

(4) As discussed in $[1,17,24-27,29,31,32,34]$, to avoid the chattering problems caused by the signum function, some continuous functions such as the sigmoid function and the saturation function are employed. However, these guidance laws are still nonsmooth, which would lower down the quality of the control system.
In this paper, we proposed a novel adaptive law to estimate the square of the target acceleration bound, based on which the smooth adaptive nonsingular fast terminal sliding mode guidance (SANFTSMG) law was derived. To the author's best knowledge, based on the existing adaptive laws, the smooth feature and finite time convergence property of the guidance laws cannot be guaranteed at the same time. The main contributions of this paper are stated as follows.

(1) With the new adaptive law, the square of the target acceleration bound is estimated, based on which not only does the proposed guidance law not exhibit singularity problem, but also the nonsmooth problem is fundamentally solved, and the chattering phenomenon is alleviated.

(2) The proposed guidance law is reliable in practice, as no prior information of target acceleration profile is required and the time to go is also needless.

(3) The finite time convergence of the system is proved both for the sliding mode reaching stage and the motion on the sliding manifold, which indicates the system states can converge fast to the small neighborhood of the origin.

(4) Faster convergence speed is achieved compared with other fast terminal sliding mode based guidance laws, as the new guidance law need not avoid chattering by using the continuous but nondifferential function, which would reduce the control precision as well as slow down the convergence speed.

This paper is organized as follows. Some important preliminaries are stated in Section 2. In Section 3, the nonlinear homing engagement geometry is stated. The main result of this paper, the SANFTSMG, is derived in Section 4, and the numerical simulations with multiple sceneries are provided in Section 5. Finally, the conclusions are offered in Section 6.

\section{Preliminary Concepts}

To begin with, several important definitions and lemmas are presented, serving as a basis for this study.

Definition 1. The nonsingular terminal sliding mode (NTSM) [26] and nonsingular fast terminal sliding mode (NFTSM) [28] can be described by the following nonlinear differential equation:

$$
\begin{aligned}
& s=x+\alpha \operatorname{sig}^{\beta}(\dot{x}), \quad \alpha>0,1<\beta<2, \\
& s=x+\alpha_{1} \operatorname{sig}^{\beta_{1}}(x)+\alpha_{2} \operatorname{sig}^{\beta_{2}}(\dot{x}), \\
& \alpha_{1}, \alpha_{2}>0, \beta_{1}>\beta_{2}, 1<\beta_{2}<2,
\end{aligned}
$$

respectively, where $x \in R, \operatorname{sig}^{\beta}(x)=|x|^{\beta} \operatorname{sign}(x)$ and $s$ is the sliding manifold. 
Remark 2. Equations (1) and (2) are not only continuous but also differentiable. Their first derivatives can be expressed as $[26,28]$

$$
\begin{aligned}
& \dot{s}=\dot{x}+\alpha \beta|\dot{x}|^{\beta-1} \ddot{x}, \\
& \dot{s}=\dot{x}+\alpha_{1} \beta_{1}|\dot{x}|^{\beta_{1}-1} \dot{x}+\alpha_{2} \beta_{2}|\dot{x}|^{\beta_{2}-1} \ddot{x} .
\end{aligned}
$$

Remark 3. Equations (1) and (2) indicate that when $s=0$, the system states $x$ and $\dot{x}$ would converge to zero simultaneously in finite time, which shows their characteristic of being nonsingular.

Lemma 4 (see [27]). Suppose the continuous positive definite function $V(t)$ satisfies the inequality

$$
\begin{aligned}
\dot{V}(t)+a V(t)+b V^{\gamma}(t) & <0, \\
t & >t_{0}, a>0, \quad b>0,0<\gamma<1,
\end{aligned}
$$

where $t_{0}$ is the initial time. Then, the system converges to the equilibrium point in finite time, and the settling time can be given by

$$
t_{f} \leq t_{0}+\frac{1}{a(1-\gamma)} \ln \frac{a V^{1-\gamma}\left(t_{0}\right)+b}{b} .
$$

Lemma 5 (see [35]). Assume that $m \geq 0, n \geq 0, p>1, q>1$ with $(1 / p)+(1 / q)=1$; then the following inequality holds:

$$
m n \leq \frac{1}{p} m^{p}+\frac{1}{q} n^{q} .
$$

\section{Problem Formulation}

3.1. Model Derivation. Consider two-dimensional engagement geometry as shown in Figure 1, where the missile (marked as $m$ ) and the target (marked as $t$ ) are regarded as point mass; the engagement dynamics equations can be described by $[29,32]$

$$
\begin{aligned}
\dot{r} & =V_{t} \cos \left(q-\gamma_{t}\right)-V_{m} \cos \left(q-\gamma_{m}\right), \\
r \dot{q} & =-V_{t} \sin \left(q-\gamma_{t}\right)+V_{m} \sin \left(q-\gamma_{m}\right), \\
\dot{\gamma}_{t} & =\frac{A_{t}}{V_{t}}, \\
\dot{\gamma}_{m} & =\frac{A_{m}}{V_{m}},
\end{aligned}
$$

where $q, \dot{q}$ denote the line of sight (LOS) angle and LOS angular rate between the missile and the target; $r, \dot{r}$ denote the relative distance and relative velocity from the missile to the target; $\gamma_{m}, \gamma_{t}$ denote the flight path angle of the missile and the target; $A_{m}, A_{t}$ denote the acceleration of the missile and the target; and $V_{m}, V_{t}$ denote the velocity of the missile and target, respectively.

Assumption 6. The autopilots and the seeker dynamics of the missile are perfect.

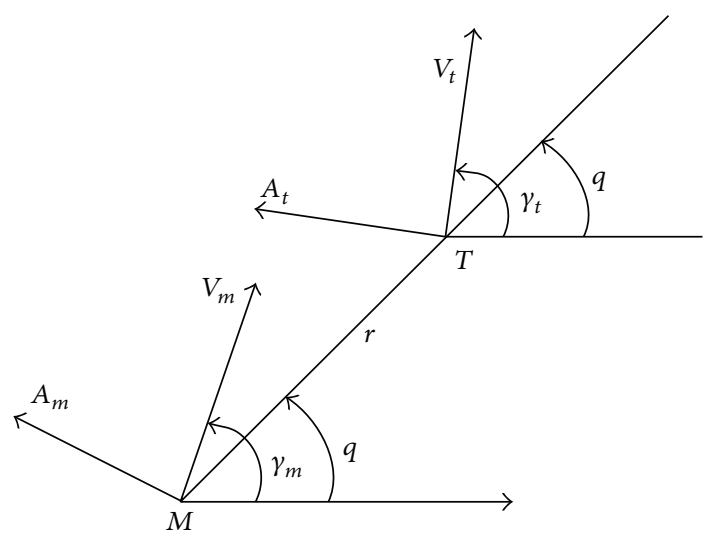

FIGURE 1: Two-dimensional engagement geometry.

Assumption 7. Suppose that $\left|A_{t}\right| \leq d_{t}$, where $d_{t}$ is unknown positive constant characterizing the upper bound of the target acceleration.

Assumption 8. Usually, the terminal guidance stage has a very short interval, especially for the engagement scenario with high speed, so we can assume the velocity of the missile $V_{m}$ and the target $V_{t}$ are constant.

Differentiating (8) with respect to time yields

$$
\ddot{q}=\frac{-2 \dot{q} \dot{r}}{r}+\frac{A_{t} \cos \left(\gamma_{t}-q\right)}{r}-\frac{A_{m} \cos \left(\gamma_{m}-q\right)}{r} .
$$

As discussed in $[29,31]$, the terminal LOS angle $q\left(t_{f}\right)$ and the required impact angle $\theta_{\text {imp }}$ have one-to-one correspondence; as a result, the problem of designing IAGL is converted to the control problem of terminal LOS $q\left(t_{e}\right)=q_{d}$, where constant $q_{d}$ denotes the desired terminal LOS angle and $t_{e}$ is the end of the terminal guidance.

Defining $x_{1}=q-q_{d}, x_{2}=\dot{q}$ and substituting them into (11) yield the state equation as follows:

$$
\begin{aligned}
& \dot{x}_{1}=x_{2}, \\
& \dot{x}_{2}=-\frac{2 \dot{r}}{r} x_{2}-\frac{u}{r}+\frac{f}{r},
\end{aligned}
$$

where $u=A_{m} \cos \left(\gamma_{m}-q\right)$ is the guidance command which should be designed to drive $x_{1} \rightarrow 0, x_{2} \rightarrow 0$ in finite time; $f=A_{t} \cos \left(\gamma_{t}-q\right)$ represents the unknown target disturbance; from Assumption 7 we can obtain $|f| \leq d_{m}$, where $d_{t}$ is unknown positive constant. The starting time of the guidance process is taken to be zero (i.e., $t=0$ ), the initial values of the state variables of (12) are denoted as $r(0), \dot{r}(0)$ and $x_{1}(0)$, $x_{2}(0)$, and the state variables of the end are denoted as $r\left(t_{e}\right)$, $\dot{r}\left(t_{e}\right)$ and $x_{1}\left(t_{e}\right), x_{2}\left(t_{e}\right)$.

Assumption 9. During the time horizon of the terminal guidance process, assume that

$$
\begin{aligned}
& \dot{r}(t)<0, \\
& r\left(t_{e}\right)<r(t)<r(0), \\
& \quad 0 \leq t \leq t_{e} .
\end{aligned}
$$


3.2. Design Objective. As discussed above, the main problem of the existing adaptive nonsingular terminal sliding mode guidance laws can be summarized as nonsmooth or noncontinuous. For example, in [32], the authors use the continuous nonsingular terminal sliding manifold; however, the employment of signum function makes the guidance law discontinuous. Similarly, in [29], the continuous sigmoid function is used to replace the signum function based on which the continuous guidance law can be obtained; however it is still nondifferential and thus nonsmooth. In this paper, the main guidelines for designing the smooth adaptive finite time guidance laws with impact angle constraints are given as follows.

(1) The guidance law is smooth as the nonsmooth signum function is no longer used.

(2) The guidance law can not only intercept the maneuvering target with small miss distance, but also achieve the desired impact angle.

(3) The LOS angle error and LOS angular rate can converge to zero in finite time.

(4) The proposed guidance law should be robust with respect to the unknown target maneuvering. That is to say, the above guidelines can also be satisfied when there exists unknown target maneuvering.

\section{Smooth Adaptive Nonsingular Fast Terminal Sliding Mode Guidance (SANFTSMG) Law}

In this section, the IAGL with target acceleration as known prior knowledge is developed first. Then the SANFTSMG based on a novel adaptive law to estimate the square of target acceleration bound is proposed, the characteristic of finite time convergence is proved, and the convergence region of the sliding manifold and the state variables are given.

\subsection{Smooth Nonsingular Fast Terminal Sliding Mode Guidance (SNFTSMG) Law}

Theorem 10. For the guidance system described by (12), if the NFTSM manifold is provided by

$$
\begin{aligned}
s=x_{1}+\alpha_{1} \operatorname{sig}^{\beta_{1}}\left(x_{1}\right)+ & \alpha_{2} \operatorname{sig}^{\beta_{2}}\left(x_{2}\right) \\
\alpha_{1}, \alpha_{2} & >0,1<\beta_{2}<2, \beta_{1}>\beta_{2}
\end{aligned}
$$

and the SNFTSMG is designed as

$$
\begin{aligned}
u= & r\left(-\frac{2 \dot{r}}{r} x_{2}+\frac{\operatorname{sig}^{2-\beta_{2}}\left(x_{2}\right)}{\alpha_{2} \beta_{2}}\left(1+\alpha_{1} \beta_{1}\left|x_{1}\right|^{\beta_{1}-1}\right)\right. \\
& \left.+k_{1} s+k_{2}|s|^{\mu} \operatorname{sign}(s)+\frac{f}{r}\right),
\end{aligned}
$$

where $k_{1}, k_{2}>0,0<\mu<1$, then the LOS angular rate converges to zero in finite time and the terminal LOS angle also converges to $q_{d}$ in finite time.
Proof. Differentiating (14) and combining (12) and (15) products,

$$
\dot{s}=-\alpha_{2} \beta_{2}\left|x_{2}\right|^{\beta_{2}-1}\left(k_{1} s+k_{2}|s|^{\mu} \operatorname{sign}(s)\right) .
$$

Let $V_{1}=1 / 2 s^{2}$ be a Lyapunov candidate; considering (16) the derivative of $V_{1}$ with respect to time yields

$$
\begin{aligned}
\dot{V}_{1} & =s \dot{s}=-\alpha_{2} \beta_{2}\left|x_{2}\right|^{\beta_{2}-1}\left(k_{1} s^{2}+k_{2}|s|^{\mu+1}\right) \\
& =-\bar{\alpha} V_{1}-\bar{\beta} V_{1}^{\bar{\gamma}},
\end{aligned}
$$

where $\bar{\alpha}=2 \alpha_{2} \beta_{2} k_{1}\left|x_{2}\right|^{\beta_{2}-1}, \bar{\beta}=2^{(\mu+1) / 2} \alpha_{2} \beta_{2} k_{2}\left|x_{2}\right|^{\beta_{2}-1}, \bar{\gamma}=$ $(\mu+1) / 2$.

Case $1\left(x_{2} \neq 0\right)$. Since $\alpha_{2}>0,1<\beta_{2}<2$ and $k_{1}, k_{2}>0$, $0<\mu<1$, then $\bar{\alpha}, \bar{\beta}>0,0<\bar{\gamma}<1$; as a result (17) has a similar form to (4); accordingly, the sliding manifold can be reached in finite time and the convergent time is given by

$$
T_{1} \leq \frac{1}{\bar{\alpha}(1-\bar{\gamma})} \ln \frac{\overline{\alpha V_{1}^{1-\bar{\gamma}}(s(0))+\bar{\beta}}}{\bar{\beta}},
$$

where $s(0)$ is the initial value of the sliding variable.

Case $2\left(x_{2}=0, s \neq 0\right)$. Substituting (15) into (12) yields

$$
\dot{x}_{2}=-k_{1} s-k_{2}|s|^{\mu} \operatorname{sign}(s) \neq 0 .
$$

Since $s \neq 0$, then the system sate variable $x_{2}$ will not always stay $x_{2}=0, s \neq 0$; thus $x_{2}=0$ is not an attractor in the reaching phase. The finite time convergence of the sliding surface can still be guaranteed. This completes the proof of Theorem 10.

4.2. Smooth Adaptive Nonsingular Fast Terminal Sliding Mode Guidance (SANFTSMG) Law. As indicated in SNTSMG (15), required input information such as $x_{1}, x_{2}, r$, and $\dot{r}$ is usually available from the seeker excepting $f$ which represents the unknown target maneuvering. In this part, an adaptive law for estimating the square of target acceleration bound is proposed based on which the SANFTSMG is derived.

Theorem 11. Consider guidance system (12) and NFTSM manifold (14), if the SANFTSMG is given by

$$
\begin{aligned}
u= & r\left(-\frac{2 \dot{r}}{r} x_{2}+\frac{\operatorname{sig}^{2-\beta_{2}}\left(x_{2}\right)}{\alpha_{2} \beta_{2}}\left(1+\alpha_{1} \beta_{1}\left|x_{1}\right|^{\beta_{1}-1}\right)\right. \\
& \left.+k_{1} s+k_{2}|s|^{\mu} \operatorname{sign}(s)+\widehat{k} k_{3} s\right),
\end{aligned}
$$

where $k_{1}, k_{2}, k_{3}>0,0<\mu<1$ and $\widehat{k}$ denotes the estimation of $k=d_{m}^{2}$, which is governed by the adaptive law

$$
\dot{\widehat{k}}=\alpha_{2} \beta_{2}\left|x_{2}\right|^{\beta-1}\left(k_{3} s^{2}-k_{4} \widehat{k}\right), \quad k_{4}>0 .
$$

Then, the following conclusions can be obtained. 
(1) The system will converge to the region $|s| \leq \Delta_{1}$ in finite time.

(2) The LOS angular rate will converge to the bounded domain $\left|x_{2}\right| \leq \Delta_{3}$ in finite time.

(3) The LOS angle will converge to the bounded domain $\left|x_{1}\right| \leq \Delta_{4}$ in finite time which implies the desired impact angle constraint is held.

Thus

$$
\begin{aligned}
& \Delta_{1}=\left(\frac{1}{4 k_{2} k_{3} r_{t_{e}}^{2}}\right)^{1 /(\mu+1)}, \\
& \Delta_{2}=\left(\frac{\Delta_{1}^{\prime}}{\alpha_{1}}\right)^{1 / \beta}, \\
& \Delta_{3}=\left(\frac{\Delta_{1}^{\prime}}{\alpha_{2}}\right)^{1 / \beta}, \\
& \Delta_{4}=\min \left\{3 \Delta_{1}, \Delta_{2}\right\},
\end{aligned}
$$

where $r_{t_{e}}$ is the detonation distance of the warhead of the intercept missile.

Proof. The proof process can be divided into three steps.

Step 1. Differentiating (14) and combining (12) and (20) yield

$$
\dot{s} \dot{s}=\alpha_{2} \beta_{2}|x|^{\beta_{2}-1}\left(-k_{1} s^{2}-k_{2}|s|^{\mu+1}+\frac{f s}{r}-\widehat{k} k_{3} s^{2}\right) .
$$

Define estimation error of the adaptive law as $\widetilde{k}=k-\widehat{k}$, and let $V_{2}=1 / 2 s^{2}+1 / 2 \widetilde{k}^{2}$ be a Lyapunov candidate. Then the derivative of $V_{2}$ with respect to time can be described as follows by combining (21) and (23):

$$
\begin{aligned}
\dot{V}_{2} & =s \dot{s}-\tilde{k} \dot{\hat{k}}=\alpha_{2} \beta_{2}\left|x_{2}\right|^{\beta_{2}-1} \\
& \cdot\left(-k_{1} s^{2}-k_{2}|s|^{\mu+1}+\frac{f s}{r}-k k_{3} s^{2}+k_{4} \hat{k} \tilde{k}\right) .
\end{aligned}
$$

Since $\alpha_{2}>0,1<\beta_{2}<2, k_{2}>0$, then $\alpha_{2} \beta_{2}\left|x_{2}\right|^{\beta_{2}-1}>0$, $k_{2}|s|^{\mu+1}>0$; thus (24) can be zoomed as

$$
\begin{aligned}
\dot{V}_{2} \leq & \alpha_{2} \beta_{2}\left|x_{2}\right|^{\beta-1} \\
& \cdot\left(-k_{1} s^{2}+\frac{d_{m}|s|}{r}-k k_{3} s^{2}+k_{4} k \widetilde{k}-k_{4} \tilde{k}^{2}\right) .
\end{aligned}
$$
that

According to Lemma 5, let $p=2, q=2$; one can imply

$$
m+n \geq 2 \sqrt{m n}, \quad m \geq 0, n \geq 0 .
$$

Thus, we can obtain the following inequalities:

$$
\begin{gathered}
k k_{3} s^{2}+\frac{1}{4 k_{3} r^{2}} \geq 2 \sqrt{\frac{k k_{3} s^{2}}{4 k_{3} r^{2}}}=\frac{d_{m}|s|}{r}, \\
\frac{1}{2}\left(k^{2}+\tilde{k}^{2}\right) \geq|k \tilde{k}| \geq k \tilde{k} .
\end{gathered}
$$

Substituting (27) and (28) into (25) yields

$$
\begin{aligned}
& \dot{V}_{2} \\
& \leq \alpha_{2} \beta_{2}\left|x_{2}\right|^{\beta_{2}-1}\left(-k_{1} s^{2}-\frac{1}{2} k_{4} \tilde{k}^{2}+\frac{1}{4 k_{3} r^{2}}+\frac{1}{2} k_{4} k^{2}\right) \\
& \leq-\alpha_{2} \beta_{2}\left|x_{2}\right|^{\beta_{2}-1}\left(\frac{\eta_{1}}{2} s^{2}+\frac{\eta_{1}}{2} \widetilde{k}^{2}\right) \\
& \quad+\alpha_{2} \beta_{2}\left|x_{2}\right|^{\beta_{2}-1}\left(\frac{1}{4 k_{3} r^{2}}+\frac{1}{2} k_{4} k^{2}\right)=-\eta V_{2}+\delta,
\end{aligned}
$$

where $\eta_{1}=\min \left\{2 k_{1}, k_{4}\right\}, \eta=\alpha_{2} \beta_{2}\left|x_{2}\right|^{\beta_{2}-1} \eta_{1}, \delta=$ $\alpha_{2} \beta_{2}\left|x_{2}\right|^{\beta_{2}-1}\left(1 / 4 k_{3} r^{2}+(1 / 2) k_{4} k^{2}\right)$ and $\eta_{1}, \eta>0$.

It can be seen that when $V_{2}>\delta / \eta, \dot{V}_{2} \leq 0$ holds, which implies that $V_{2}$ is bounded. Hence, it can be concluded that the sliding mode variable $s$ and the estimation error $\tilde{k}$ are all bounded. Let $|\widetilde{k}| \leq \xi$ with $\xi$ being an unknown positive constant. This conclusion will be used in the next step.

Step 2. Consider guidance system (12) and SANFTSMG (20), redefine Lyapunov function $V_{3}=1 / 2 s^{2}$. Differentiating $V_{3}$ with respect to time and substituting (23) and (27) into the equation give

$$
\begin{aligned}
& \dot{V}_{3}=\alpha_{2} \beta_{2}\left|x_{2}\right|^{\beta_{2}-1}\left(-k_{1} s^{2}-k_{2}|s|^{\mu+1}+\frac{f s}{r}-\widehat{k} k_{3} s^{2}\right) \\
& \leq \alpha_{2} \beta_{2}\left|x_{2}\right|^{\beta_{2}-1}\left(-k_{1} s^{2}-k_{2}|s|^{\mu+1}+\xi k_{3} s^{2}+\frac{1}{4 k_{3} r^{2}}\right) \\
& =-\left(\bar{k}_{1}^{\prime}-\bar{\xi}_{1}^{\prime}\right) s^{2}-\left(\bar{k}_{2}^{\prime}-\bar{\xi}_{2}^{\prime}\right)|s|^{\mu+1} \\
& =-\bar{\alpha}_{2} V_{3}-\bar{\beta}_{2} V_{3}^{\bar{\gamma}^{\prime}},
\end{aligned}
$$

where $\bar{k}_{1}^{\prime}=\alpha_{2} \beta_{2} k_{1}\left|x_{2}\right|^{\beta_{2}-1}, \bar{k}_{2}^{\prime}=\alpha_{2} \beta_{2} k_{2}\left|x_{2}\right|^{\beta_{2}-1}, \bar{\xi}_{1}^{\prime}=$ $\alpha_{2} \beta_{2} \xi k_{3}\left|x_{2}\right|^{\beta_{2}-1}$, and $\bar{\xi}_{2}^{\prime}=\alpha_{2} \beta_{2}\left|x_{2}\right|^{\beta_{2}-1} / 4 k_{3} r^{2}|s|^{\mu+1}$

$$
\begin{aligned}
& \bar{\alpha}_{2}=2\left(\bar{k}_{1}^{\prime}-\bar{\xi}_{1}^{\prime}\right), \\
& \bar{\beta}_{2}=2^{\bar{\gamma}}\left(\bar{k}_{2}^{\prime}-\bar{\xi}_{2}^{\prime}\right), \\
& \bar{\gamma}^{\prime}=\frac{\mu+1}{2} .
\end{aligned}
$$

Case $1\left(x_{2} \neq 0\right)$. Choose $k_{1}>\xi k_{3}$, and $k_{2}>1 / 4 k_{3} r^{2}|s|^{\mu+1}$; then $\bar{\alpha}_{2}, \bar{\beta}_{2}>0,0<\bar{\gamma}^{\prime}<1$, as a result (30) has a similar form to (4); accordingly, the sliding manifold can be reached in finite time and the convergent time is given by

$$
T_{3} \leq \frac{1}{\bar{\alpha}_{2}\left(1-\bar{\gamma}^{\prime}\right)} \ln \frac{\bar{\alpha}_{2} V_{4}^{1-\bar{\gamma}^{\prime}}(s(0))+\bar{\beta}_{2}}{\bar{\beta}_{2}}
$$

and the sliding mode variable will converge to

$$
|s| \leq\left(\frac{1}{4 k_{2} k_{3} r^{2}}\right)^{1 /(\mu+1)} \leq\left(\frac{1}{4 k_{2} k_{3} r_{t_{e}}^{2}}\right)^{1 /(\mu+1)}=\Delta_{1} .
$$




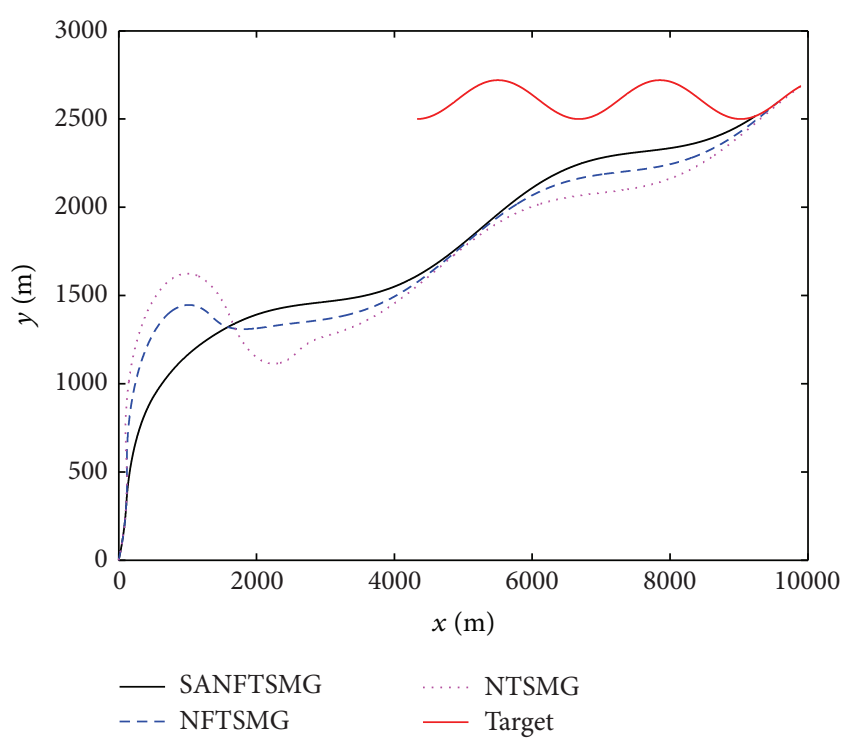

FIGURE 2: Trajectories of missile and target (Case 1).

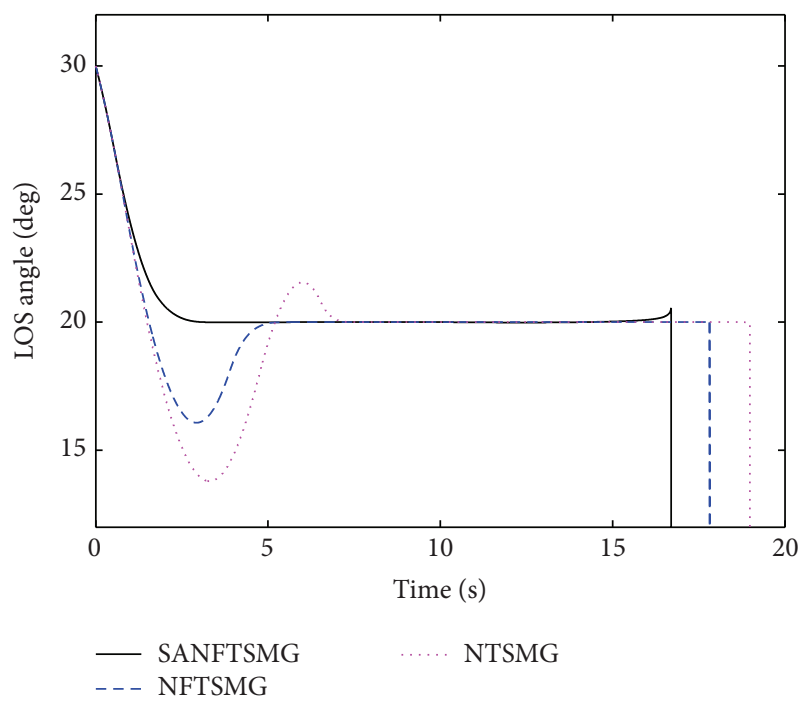

FIgURe 3: LOS angle (Case 1).

Case $2\left(x_{2}=0, s \neq 0\right)$. Substituting (20) into (12) yields

$$
\dot{x}_{2}=-k_{1} s-k_{2}|s|^{\mu} \operatorname{sign}(s)-\widehat{k} k_{3} s+\frac{f}{r} .
$$

Similarly to expression (19), $x_{2}=0$ is not an attractor in the reaching phase. The finite time convergence of the sliding surface can still be guaranteed.

Step 3. Equation (14) can be rewritten as the following two forms:

$$
\begin{aligned}
& x_{1}+\left|x_{1}\right|^{\beta_{1}} \operatorname{sign}\left(x_{1}\right)\left(\alpha_{1}-\frac{s}{\left|x_{1}\right|^{\beta_{1}} \operatorname{sign}\left(x_{1}\right)}\right) \\
& +\alpha_{2}\left|x_{2}\right|^{\beta_{2}} \operatorname{sign}\left(x_{2}\right)=0,
\end{aligned}
$$

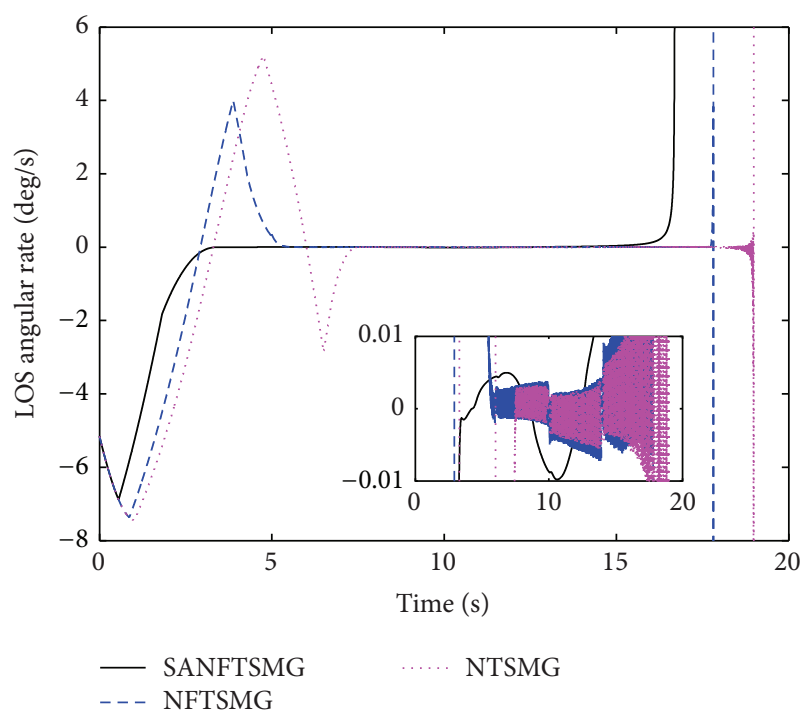

Figure 4: LOS angular rate (Case 1).

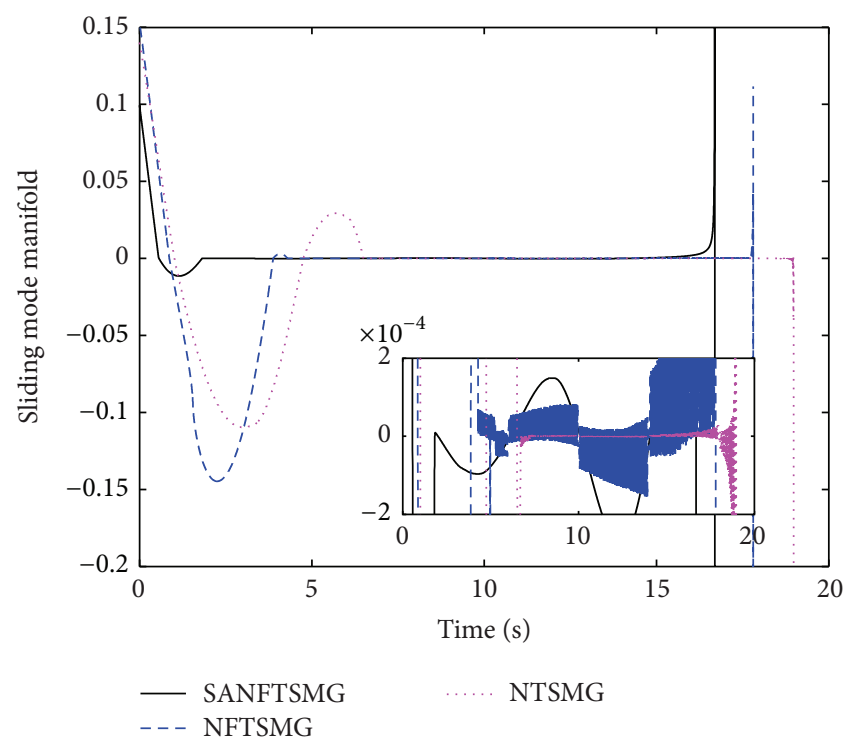

FIGURE 5: Sliding mode manifold (Case 1).

$$
\begin{aligned}
x_{1} & +\alpha_{1}\left|x_{1}\right|^{\beta_{1}} \operatorname{sign}\left(x_{1}\right) \\
& +\left|x_{2}\right|^{\beta_{2}} \operatorname{sign}\left(x_{2}\right)\left(\alpha_{2}-\frac{s}{\left|x_{2}\right|^{\beta_{2}} \operatorname{sign}\left(x_{2}\right)}\right)=0 .
\end{aligned}
$$

For (35), when $\alpha_{1}-s /\left|x_{1}\right|^{\beta_{1}} \operatorname{sign}\left(x_{1}\right)>0$, (35) has a similar form to NFTSM (2); thus we can get that the system state $x_{1}$ will converge to the region

$$
\left|x_{1}\right| \leq\left(\frac{\Delta_{1}}{\alpha_{1}}\right)^{1 / \beta_{1}}=\Delta_{2} .
$$

In a similar way, from (36) we can obtain

$$
\left|x_{2}\right| \leq\left(\frac{\Delta_{1}}{\alpha_{2}}\right)^{1 / \beta_{2}}=\Delta_{3} .
$$



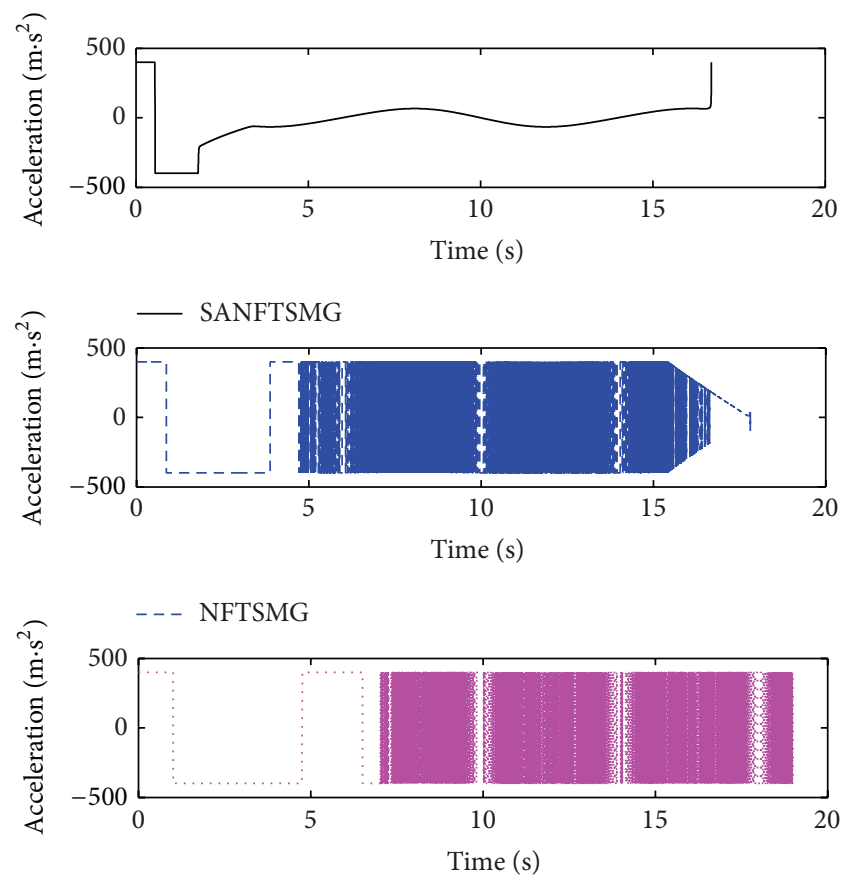

..... NTSMG

Figure 6: Missile acceleration (Case 1).

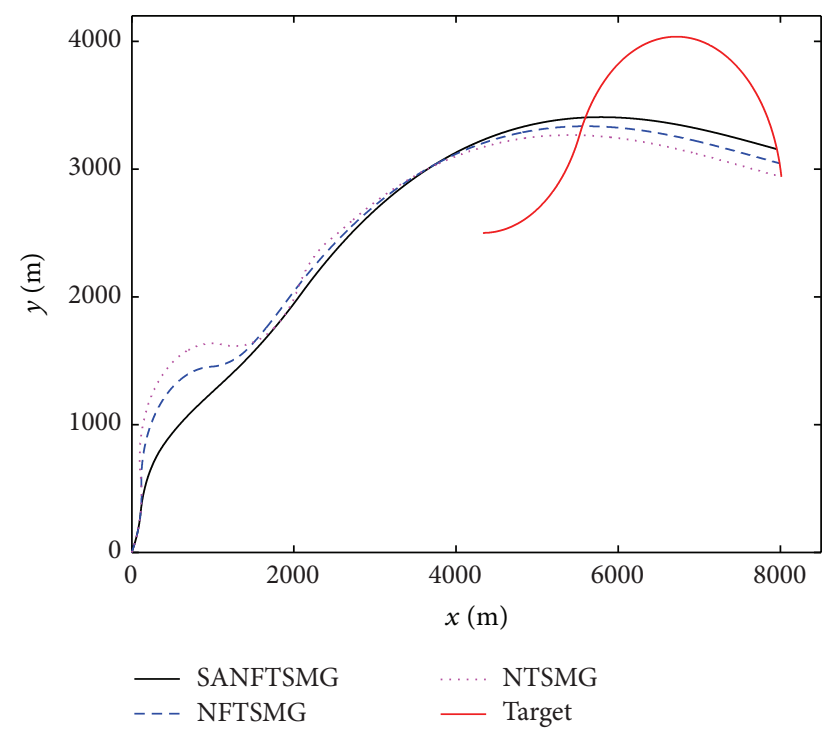

FIGURE 7: Trajectories of missile and target (Case 2).

Based on (33), (37), and (38), the convergence region of LOS angle can also be given by

$$
\begin{aligned}
\left|x_{1}\right| & \leq\left.\left|s-\alpha_{1}\right| x_{1}\right|^{\beta_{1}} \operatorname{sign}\left(x_{1}\right)-\alpha_{2}\left|x_{2}\right|^{\beta_{2}} \operatorname{sign}\left(x_{2}\right) \mid \\
& \leq 3 \Delta_{1} .
\end{aligned}
$$

Combining (37) and (39), we can get the following conclusion:

$$
\left|q-q_{d}\right|=\left|x_{1}\right| \leq \min \left\{3 \Delta_{1}, \Delta_{2}\right\}=\Delta_{4} .
$$

This completes the proof of Theorem 11.

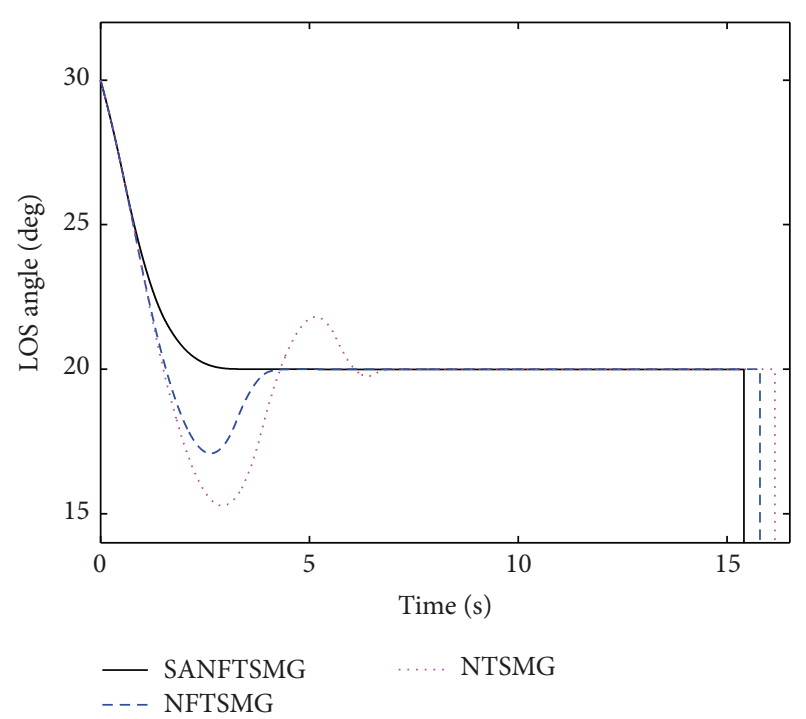

FIgURE 8: LOS angle (Case 2).

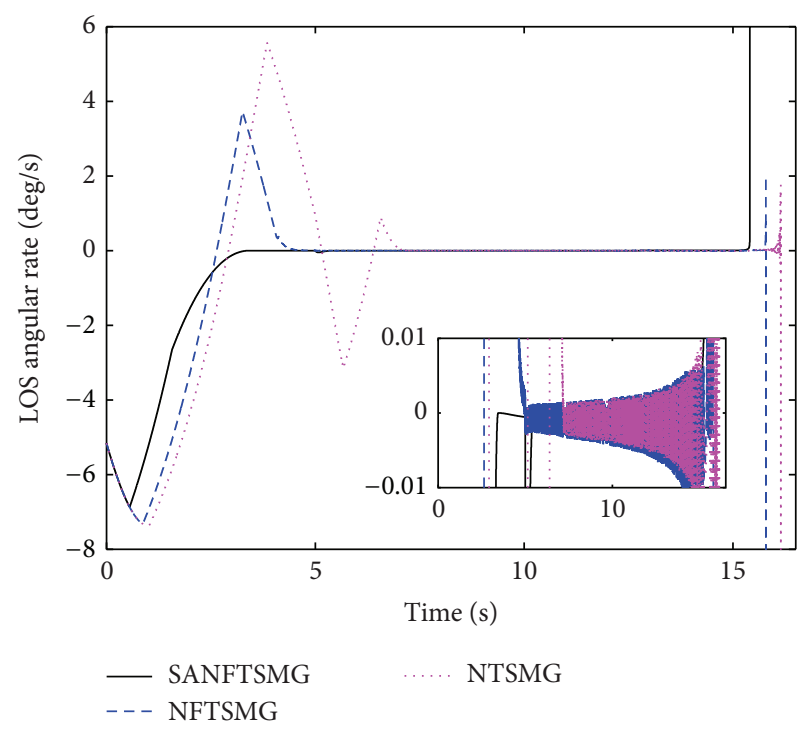

FIgURE 9: LOS angular rate (Case 2).

Remark 12. From (20), it can be observed that the SANFTSMG does not contain the negative exponent term about the system states, so it is a nonsingular guidance law.

Remark 13. The new adaptive law avoids the employment of the nonsmooth signum function, so the SANFTSMG is inherent smooth guidance law.

Remark 14. There do exist nonsingular terminal sliding mode guidance laws [29,32]; because they are nonsmooth inherent, usually the accuracy of the sliding manifold is sacrificed for solving the chattering problem. From this point of view, convergent speed of the SANFTSMG is faster; as a result the trajectory of the missile under SANFTSMG is shorter and its average acceleration command is smaller. 


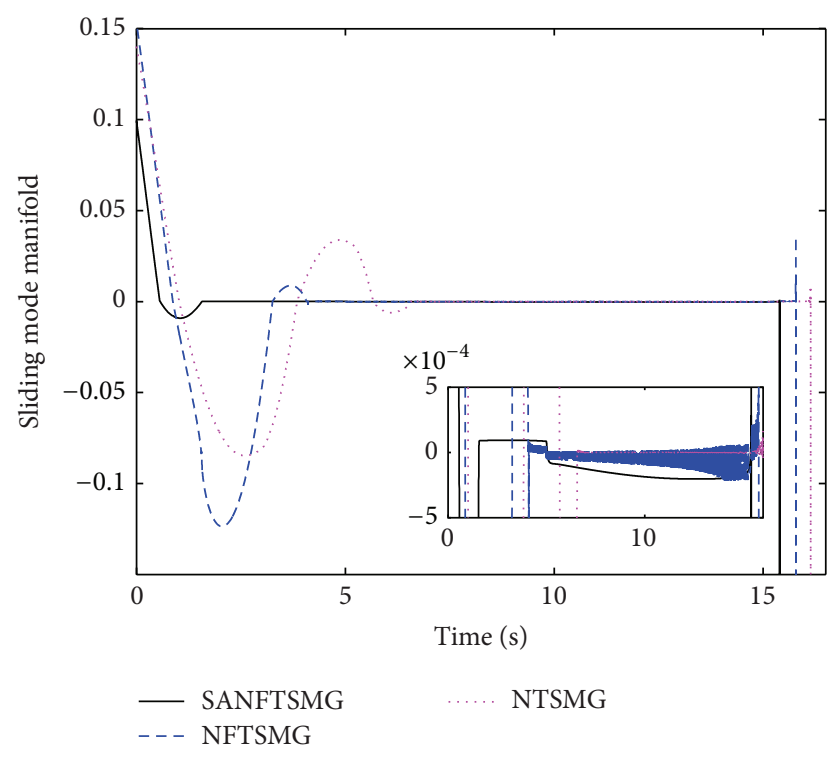

FIGURE 10: Sliding mode manifold (Case 2).
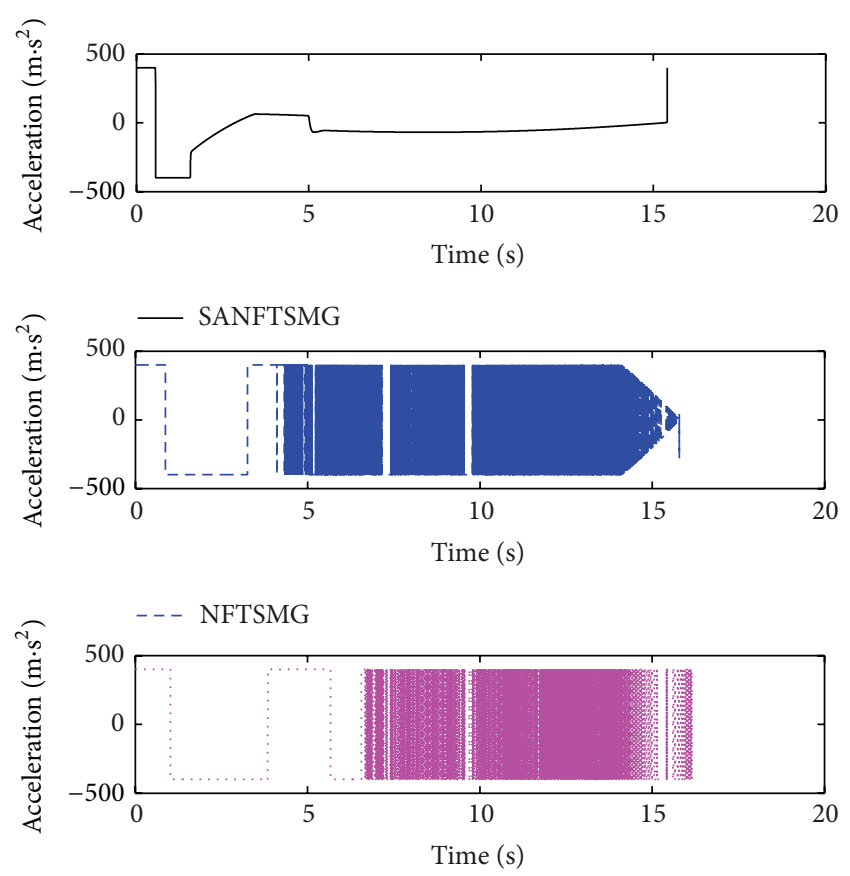

NTSMG

FIgURE 11: Missile acceleration (Case 2).

Remark 15. The expression (20) can be rewritten as

$$
u=r\left(-N \frac{\dot{r}}{r} x_{2}+L\right)
$$

where $N=2-\left(\left|x_{2}\right|^{2-\beta_{2}} / \alpha_{2} \beta_{2} t_{\mathrm{go}}\right)\left(1+\alpha_{1} \beta_{1}\left|x_{1}\right|^{\beta_{1}-1}\right), L=$ $k_{1} s_{2}+k_{2}|s|^{\mu} \operatorname{sign}(s)+\widehat{k} k_{3} s, t_{\mathrm{go}}=r / \dot{r}$, which implies the SANFTSMG can be regarded as a modified PN guidance with a time-varying navigation ratio $N$ and a compensation term $L$.

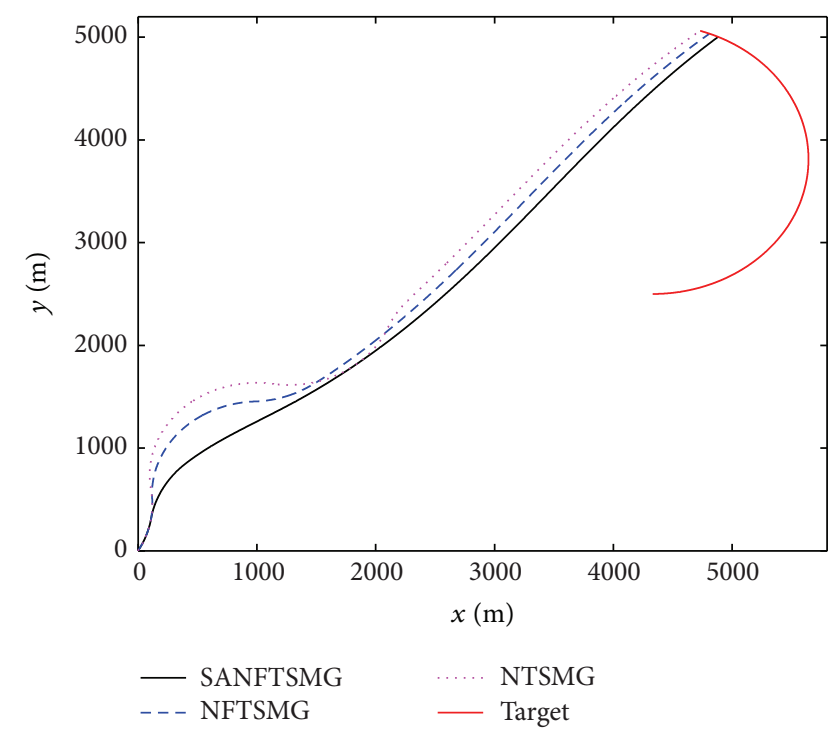

FIgUre 12: Trajectories of missile and target (Case 3).

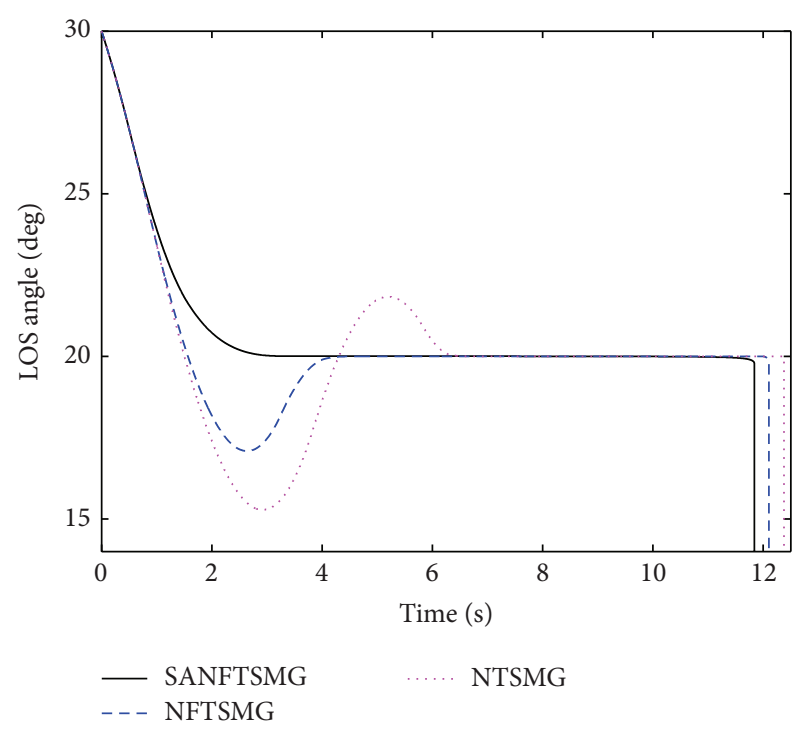

Figure 13: LOS angle (Case 3).

\section{Numerical Simulation}

To show the good performance of the SANFTSMG, the simulation results are compared with three existing TSMC based methods presented in this section.

In [32], the guidance law (NFTSMG) is designed as

$$
\begin{aligned}
s= & x_{2}+\alpha_{1} x_{1}+\alpha_{2} \beta\left(x_{1}\right), \\
a_{m} & =\frac{r}{\cos \left(q-\gamma_{m}\right)}\left(-\frac{2 \dot{r}}{r} x_{2}+\alpha_{1} x_{2}+\alpha_{2} \bar{\beta}\left(x_{1}\right)\right. \\
& \left.+\widehat{\Delta} \sigma \operatorname{sign}(s)+k_{1} \operatorname{sig}^{\gamma_{1}}(s)+k_{2} s\right),
\end{aligned}
$$




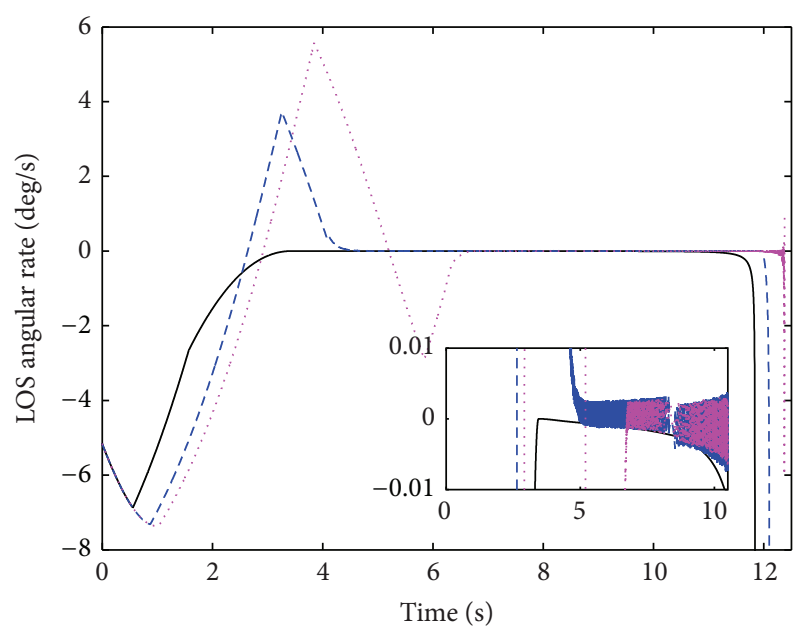

- SANFTSMG

- - NFTSMG

FIGURE 14: LOS angular rate (Case 3).

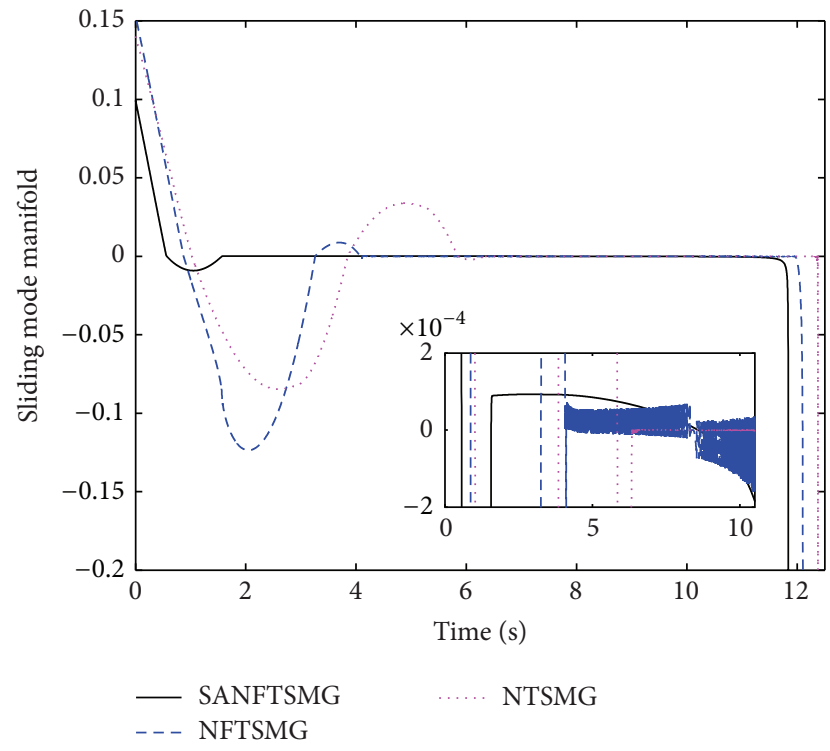

FIGURE 15: Sliding mode manifold (Case 3).

$$
\begin{aligned}
& \bar{\beta}\left(x_{1}\right)= \begin{cases}\gamma\left|x_{1}\right|^{\gamma-1} x_{2} & \left|x_{1}\right|>\eta \\
r_{1} x_{2}+2 r_{2} x_{1} x_{2} \operatorname{sign}\left(x_{1}\right) & \left|x_{1}\right| \leq \eta,\end{cases} \\
& \dot{\bar{\Delta}}=\sigma|s|, \quad \widehat{\Delta}(0)>0,
\end{aligned}
$$

where $\alpha_{1}=0.5, \alpha_{2}=0.5, \gamma=2 / 3, \sigma=1.1, k_{1}=6$, $k_{2}=2, \gamma_{1}=9 / 10, \eta=0.001$. To overcome the disadvantage of chattering due to the discontinuous signum function $\operatorname{sign}(s)$, the authors of [32] use a continuous sigmoid function to
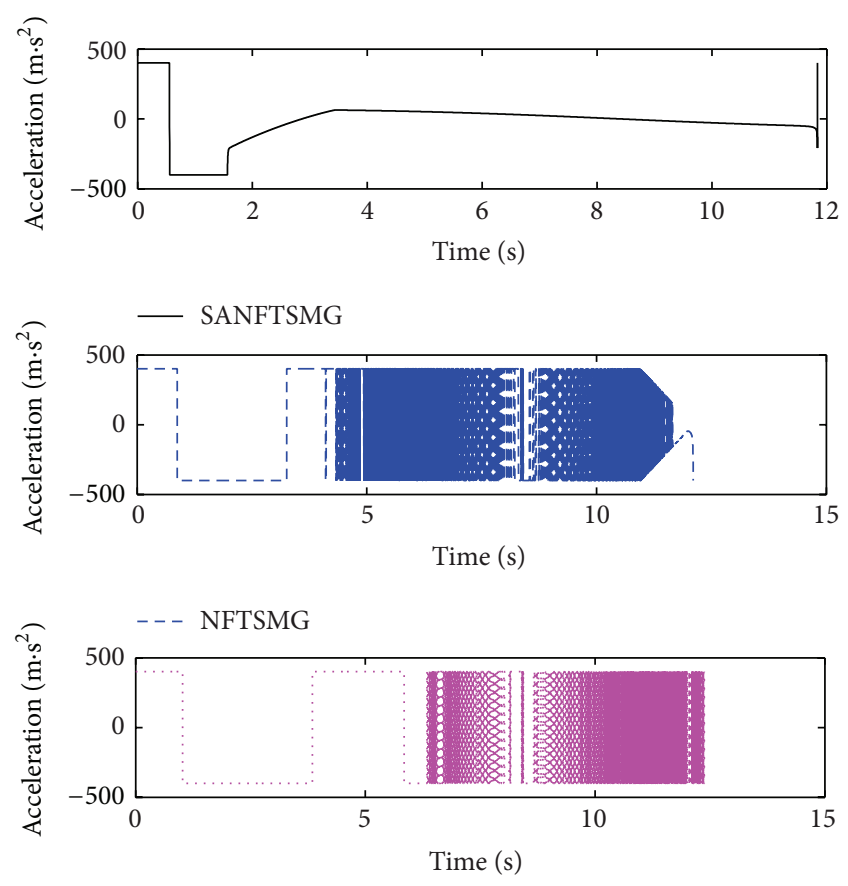

NTSMG

FIGURE 16: Missile acceleration (Case 3).

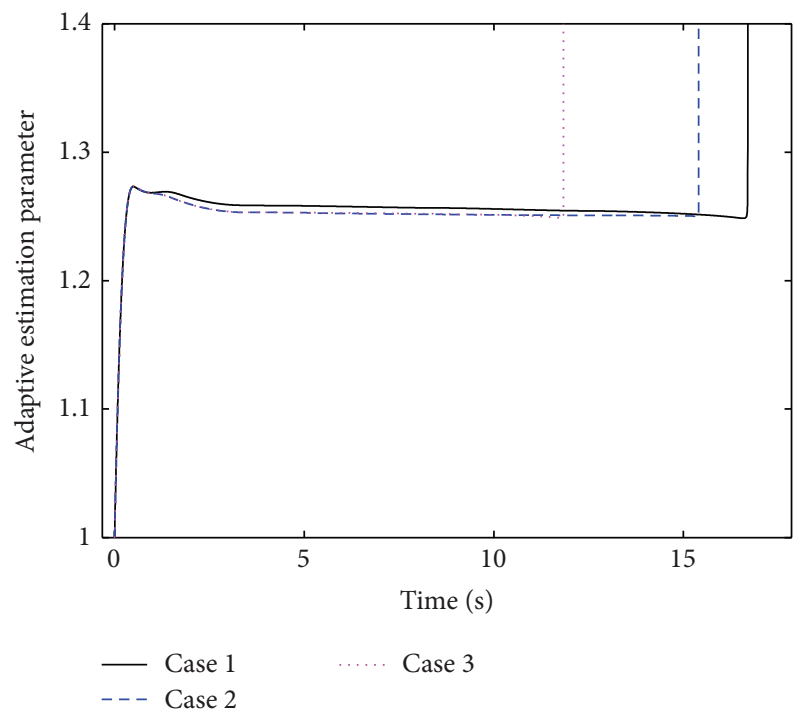

FIgURE 17: Trajectories of missile and target (Case 3).

improve its performance; we denote the modified NFTSMG as MNFTMG, which is described as

$$
\begin{aligned}
a_{m} & =\frac{r}{\cos \left(q-\gamma_{m}\right)}\left(-\frac{2 \dot{r}}{r} x_{2}+\alpha_{1} x_{2}+\alpha_{2} \bar{\beta}\left(x_{1}\right)\right. \\
& \left.+\widehat{\Delta} \sigma \operatorname{sgm}(s)+k_{1} \operatorname{sig}^{\gamma_{1}}(s)+k_{2} s\right),
\end{aligned}
$$




$$
\operatorname{sgm}(s)= \begin{cases}\operatorname{sign}(s) & |s|>\delta \\ 2\left(\frac{1}{1+\exp ^{-a s}}-\frac{1}{2}\right) & |s| \leq \delta\end{cases}
$$

where $a=1 / \delta, \delta=0.002$.

In [29], the guidance law (NTSMG) is proposed as

$$
\begin{aligned}
s= & x_{1}+\alpha\left|x_{2}\right|^{\beta} \operatorname{sign}\left(x_{2}\right), \quad \alpha>0, \quad 1<\beta<2, \\
a_{m} & =\frac{r}{\cos \left(q-\gamma_{m}\right)}\left(-\frac{2 \dot{r}}{r} x_{2}+\frac{\operatorname{sig}^{2-\beta}\left(x_{2}\right)}{\alpha \beta}\right. \\
& \left.+\frac{\widehat{k} k_{1} \operatorname{sign}(s)}{r}+\frac{k_{2} \operatorname{sign}(s)}{r}\right), \\
\dot{\hat{k}} & =\frac{\alpha \beta k_{1}}{r}\left|x_{2}\right|^{\beta-1}|s|,
\end{aligned}
$$

where $\alpha=1, \beta=7 / 5, k_{1}=2, k_{2}=1800, \delta=0.01$. In similar way, the discontinuous signum function $\operatorname{sign}(s)$ is replaced with the continuous saturation function, and a modified adaptive law is used; then the modified NTSMG (denoted as MNTSMG) can be described as

$$
\begin{aligned}
& a_{m}=\frac{r}{\cos \left(q-\gamma_{m}\right)}\left(-\frac{2 \dot{r}}{r} x_{2}+\frac{\operatorname{sig}^{2-\beta}\left(x_{2}\right)}{\alpha \beta}\right. \\
& \left.+\frac{\widehat{k} k_{1} \operatorname{sat}(s)}{r}+\frac{k_{2} \operatorname{sat}(s)}{r}\right), \\
& \dot{\hat{k}}= \begin{cases}\frac{\alpha \beta k_{1}}{r}\left|x_{2}\right|^{\beta-1}|s| & |s|>v \\
0 & |s| \leq v,\end{cases}
\end{aligned}
$$

$$
\widehat{k}(0)=100, v=0.05
$$

$\operatorname{sat}(s)= \begin{cases}\operatorname{sign}(s) & |s|>\delta \\ \frac{s}{\delta} & |s| \leq \delta .\end{cases}$

In [33], the extended state observer based guidance law (ETSMG) is given as

$$
\begin{aligned}
s= & x_{1}+k_{1}\left|x_{1}\right|^{\alpha_{1}} \operatorname{sign}\left(x_{1}\right)+k_{2}\left|x_{2}\right|^{\alpha_{2}} \operatorname{sign}\left(x_{2}\right), \\
a_{m}= & \frac{r}{\cos \left(q-\gamma_{m}\right)}\left(\frac{1}{k_{2} a_{2}}\left|x_{2}\right|^{2-a_{2}} \operatorname{sign}\left(x_{2}\right)\right. \\
& \cdot\left(1+k_{1} a_{1}\left|x_{1}\right|^{a_{1}-1}\right)-\frac{2 \dot{r}}{r} x_{2}+\frac{z_{2}}{r} \\
& \left.+\frac{\alpha s+\beta|s|^{\gamma} \operatorname{sign}(s)}{r}\right), \\
\dot{z}_{1}= & z_{2}-\beta_{01} e_{1}-\dot{r} \dot{x}_{1}-A_{m} \cos \left(q-\gamma_{m}\right), \\
\dot{z}_{2}= & -\beta_{02} e_{1},
\end{aligned}
$$

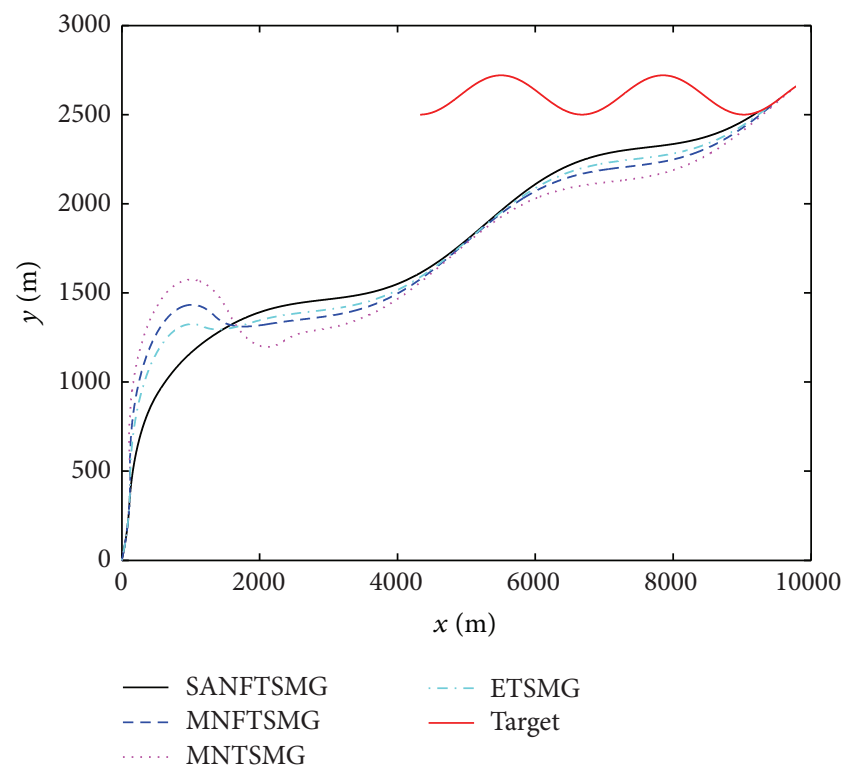

Figure 18: Trajectories of missile and target (Case 1).

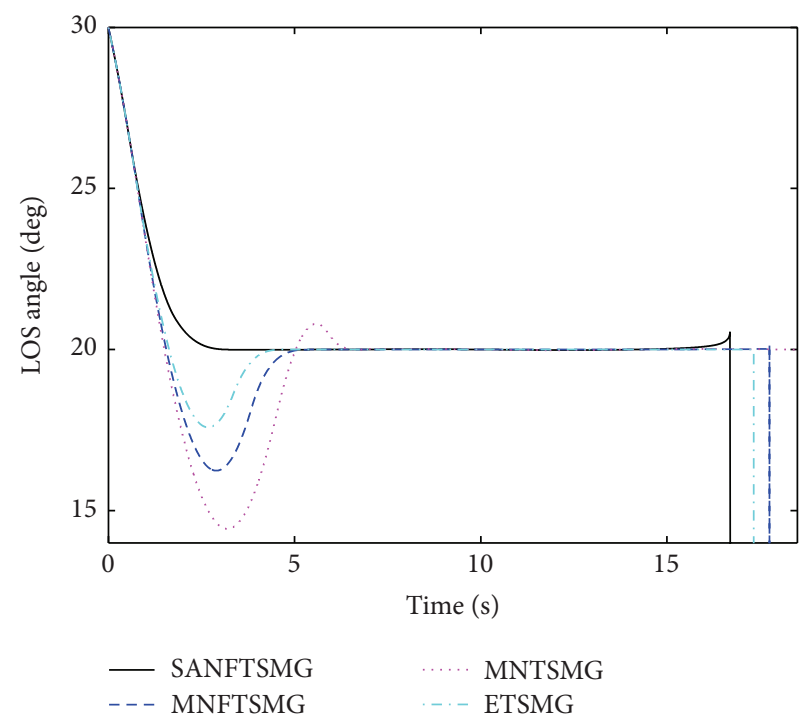

Figure 19: LOS angle (Case 1).

where $k_{1}=1, k_{2}=2, \alpha_{1}=3, \alpha_{2}=1.5, \alpha=\beta=500, \gamma=0.6$, $\beta_{01}=50, \beta_{02}=1800$.

The design parameters of the SANFTSMG are chosen as $\alpha_{1}=30, \alpha_{2}=2.65, \beta_{1}=60, \beta_{2}=1.48, k_{1}=4, k_{2}=0.5$, $k_{3}=118, k_{4}=0.01$, and $\mu=0.68$. The maximum acceleration of the missile is $40 \mathrm{~g} ; g$ is the acceleration of gravity ( $g=$ $9.8 \mathrm{~m} / \mathrm{s}^{2}$ ). For comparison of the simulation results, the initial conditions and the simulation scenarios in literature [32] are used here for all of the six guidance laws (SANFTSMG, NFTSMG, MNFTSMG, NTSMG, MNTSMG, and ETSMG). The initial condition is given in Table 1 .

In order to verify the effectiveness of the proposed guidance law, as described in [32], three different target acceleration profiles are considered as given below. 


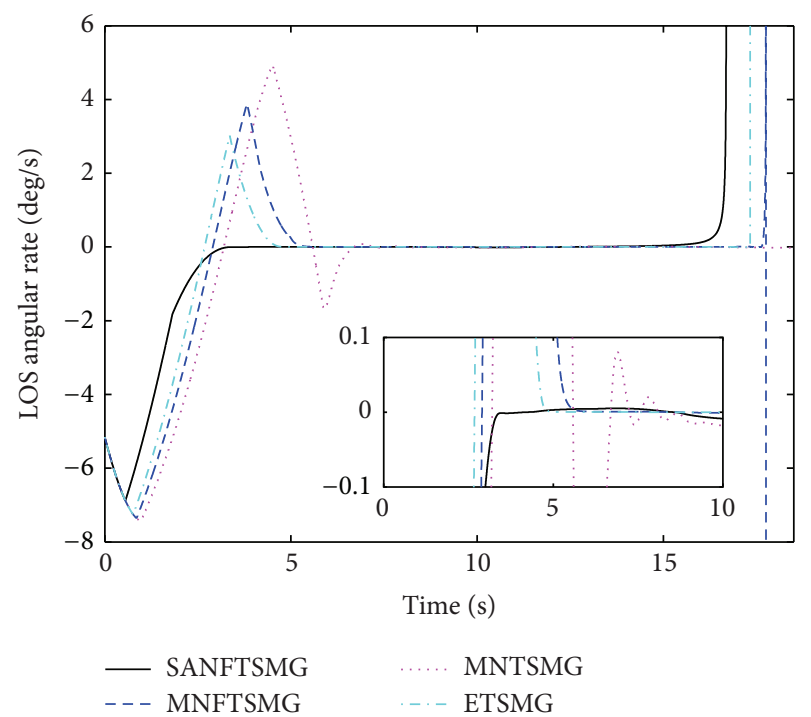

FIgURE 20: LOS angular rate (Case 1).

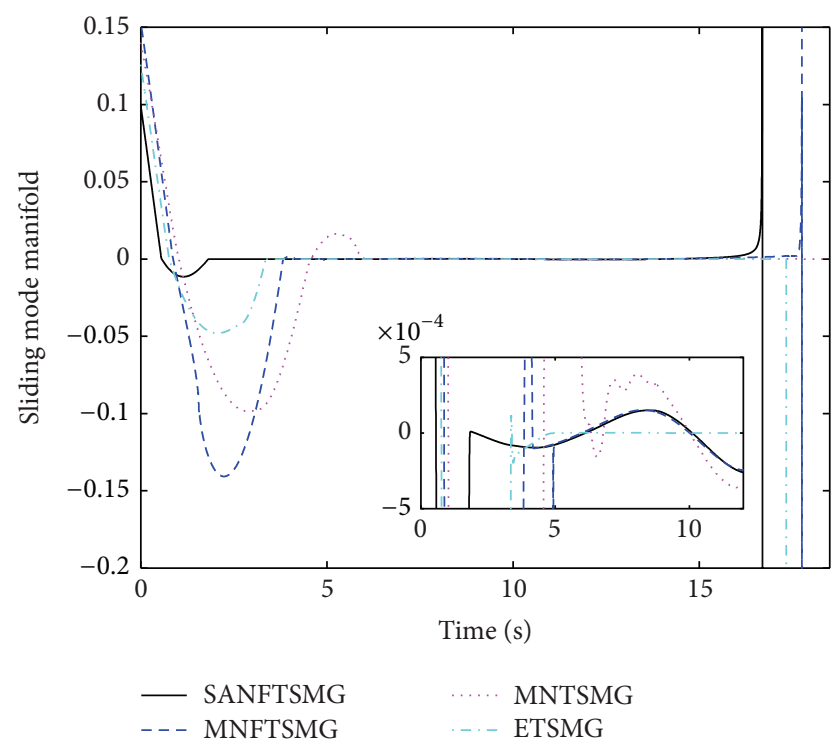

FIGURE 21: Sliding mode manifold (Case 1).

Case 1. Consider the following: $a_{t}=7 g \cos (\pi t / 4) \mathrm{m} / \mathrm{s}^{2}$.

Case 2. Consider the following: $a_{t}=7 \mathrm{~g} \mathrm{~m} / \mathrm{s}^{2}$ for $t>5 \mathrm{~s}$ and $a_{t}=-7 \mathrm{~g} \mathrm{~m} / \mathrm{s}^{2}$ for $t \geq 5 \mathrm{~s}$.

Case 3. Consider the following: $a_{t}=7 \mathrm{~g} \mathrm{~m} / \mathrm{s}^{2}$.

On the other hand, to evaluate the efficiency of the above five guidance laws, a concept of average absolute acceleration (AAA) [33] of missile is employed as

$$
a_{\mathrm{ME}}=\frac{1}{N} \sum_{k=1}^{N}\left|a_{m}(k)\right|
$$

TABLE 1: The initial condition for the missile and target.

\begin{tabular}{cccccccc}
\hline$x_{m}(0)$ & $0 \mathrm{~m}$ & $\gamma_{m}(0)$ & $60^{\circ}$ & $x_{t}(0)$ & $2500 \sqrt{3} \mathrm{~m}$ & $\gamma_{t}(0)$ & $0^{\circ}$ \\
$y_{m}(0)$ & $0 \mathrm{~m}$ & $V_{m}$ & $600 \mathrm{~m} / \mathrm{s}$ & $y_{t}(0)$ & $2500 \mathrm{~m}$ & $V_{t}$ & $300 \mathrm{~m} / \mathrm{s}$ \\
\hline
\end{tabular}

TABLE 2: Summary of simulation results in Case 1.

\begin{tabular}{lcccc}
\hline $\begin{array}{l}\text { Guidance } \\
\text { law }\end{array}$ & $\begin{array}{c}\text { Interception } \\
\text { time }(\mathrm{s})\end{array}$ & $\begin{array}{c}\text { Miss } \\
\text { distance } \\
(\mathrm{m})\end{array}$ & $\begin{array}{c}\text { LOS angel } \\
\left({ }^{\circ}\right)\end{array}$ & AAA $\left(\mathrm{m} / \mathrm{s}^{2}\right)$ \\
\hline SANFTSMG & 16.697 & 0.112 & 20.146 & 89.8900 \\
NFTSMG & 17.815 & 0.077 & 20.064 & 372.4544 \\
NTSMG & 18.985 & 0.003 & 19.955 & 400.0000 \\
\hline
\end{tabular}

TABLE 3: Summary of simulation results in Case 2.

\begin{tabular}{lcccc}
\hline $\begin{array}{l}\text { Guidance } \\
\text { law }\end{array}$ & $\begin{array}{c}\text { Interception } \\
\text { time }(\mathrm{s})\end{array}$ & $\begin{array}{c}\text { Miss } \\
\text { distance } \\
(\mathrm{m})\end{array}$ & $\begin{array}{c}\text { LOS angel } \\
\left({ }^{\circ}\right)\end{array}$ & AAA $\left(\mathrm{m} / \mathrm{s}^{2}\right)$ \\
\hline SANFTSMG & 15.403 & 0.007 & 19.997 & 90.8752 \\
NFTSMG & 15.798 & 0.212 & 20.009 & 379.6671 \\
NTSMG & 16.147 & 0.180 & 20.034 & 400.0000 \\
\hline
\end{tabular}

TABLE 4: Summary of simulation results in Case 3.

\begin{tabular}{lcccc}
\hline $\begin{array}{l}\text { Guidance } \\
\text { law }\end{array}$ & $\begin{array}{c}\text { Interception } \\
\text { time }(\mathrm{s})\end{array}$ & $\begin{array}{c}\text { Miss } \\
\text { distance } \\
(\mathrm{m})\end{array}$ & $\begin{array}{c}\text { LOS angel } \\
\left({ }^{\circ}\right)\end{array}$ & AAA $\left(\mathrm{m} / \mathrm{s}^{2}\right)$ \\
\hline SANFTSMG & 11.840 & 0.012 & 19.798 & 89.6342 \\
NFTSMG & 12.105 & 0.013 & 19.832 & 381.7468 \\
NTSMG & 12.378 & 0.391 & 19.984 & 400.0000 \\
\hline
\end{tabular}

where $N$ represents the total simulation steps and $a_{m}(k)$ denotes the $k$ th step value of $a_{m}$ in simulation.

5.1. Simulation of SANFTSMG, NFTSMG, and NTSMG. In this section, the simulations are carried out for the target acceleration profiles of Case 1 to Case 3 for comparison of the effectiveness of the SANFTSMG, NFTSMG, and NTSMG. The initial condition for the missile and target is shown in Table 1, the desired terminal LOS angle is selected as $20^{\circ}$, and the simulation results are shown in Figures $2-17$ and Tables $2-4$, respectively.

The trajectories of the missile and the target for Cases 1-3 are shown in Figures 2, 7, and 12, respectively, which imply that the SANFTSMG, NFTSMG, and NTSMG can all ensure that the missile intercepts the target in any of the three cases successfully, and the trajectory under SANFTSMG is the most gentle which implies that the missile can intercept the target earliest using this kind of guidance law; this conclusion is also summarized in the second column of Tables 2-4.

From Figures 3, 8, and 13, we can observe that these three kinds of guidance laws can all guarantee that the LOS angle converges to the neighborhood of the desired terminal 

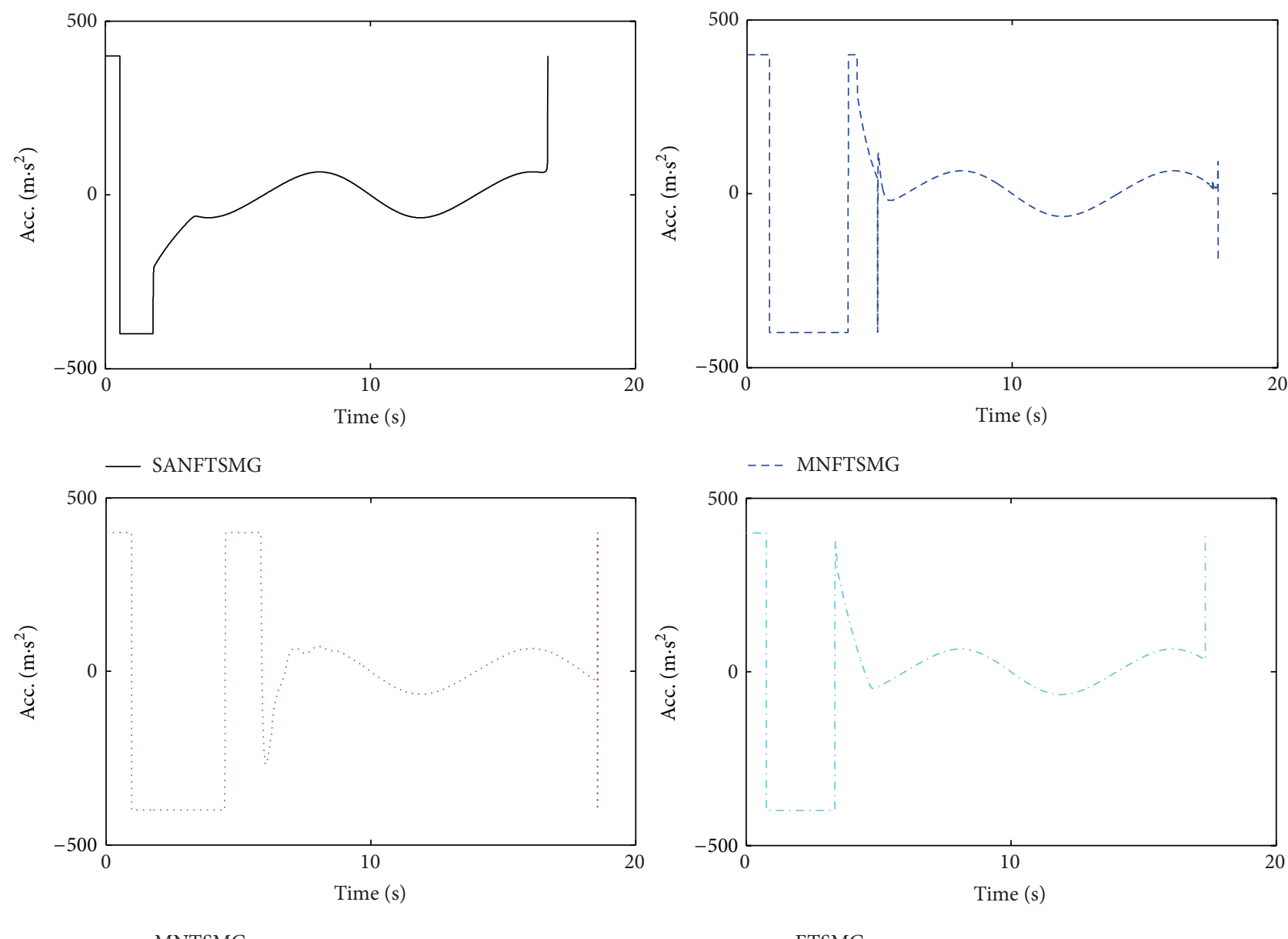

MNTSMG

ETSMG

FIgURE 22: Missile acceleration (Case 1).

LOS angle in finite time and then maintains the states until the missile intercepts the target accurately. Furthermore, we can also notice that the SANFTSMG is the earliest one that ensures that the LOS angle converges to $20^{\circ}$, followed by the NFTSMG and NTSMG in order. Figures 4, 9, and 14 indicate that, for the target acceleration profiles of Case 1 to Case 3, the SANFTSMG, NFTSMG, and NTSMG can all ensure the LOS angular rate converges to the neighborhood of zero rapidly in finite time, and compared with other two methods the convergent speed of the SANFTSMG is the fastest. In addition, we can also see from Figures 4, 9, and 14 that the curves of the LOS angular rate under the NFTSMG and NTSMG both have peaks in the first 5 seconds of the guidance process, which leads to the requirement of a longer time of saturation of overload command than the SANFTSMG during the first 5 seconds; this can be found in Figures 6, 11, and 16. From Figures 5, 10, and 15, we can find that all the three methods can ensure the sliding manifold converges to the neighborhood of zero fast in finite time for the target acceleration profiles of Case 1 to Case 3. The convergent speed of the SANFTSMG is the fastest, followed by the NFTSMG and NTSMG in order. As shown in Figures 6, 11, and 16, it can be observed that there are acceleration saturation problems in all the three cases under the SANFTSMG, NFTSMG, and NTSMG, among which the saturation time of the acceleration command of SANFTSMG is very short, while the acceleration commands of the other two methods are almost saturated during the whole flight. From Tables 2-4, we can clearly find that the interception time taken by the SANFTSMG is shorter than the other two methods, the miss distance obtained by the SANFTSMG is least, the terminal LOS angel accuracy of the three methods in this section is similar, and the average absolute acceleration of the SANFTSMG is much smaller than the other two methods. That is to say, under the SANFTSMG, the missile can intercept the target earliest using the least actuator energy and obtain the smallest miss distance. In addition, it can be seen clearly from Figures 4, 5, 9, 10, 14, and 15 that the SANFTSMG is completely smooth as the LOS angular rate and sliding manifold converges smoothly using this kind of guidance law. From Figure 17, we can see that the adaptive estimation parameter $\widehat{k}$ (defined in adaptive law (21)) representing the square of target acceleration bound converges to the neighborhood of a constant fast in finite time for the target acceleration profiles of Case 1 to Case 3, which proves that $\widetilde{k}$ is bounded. 


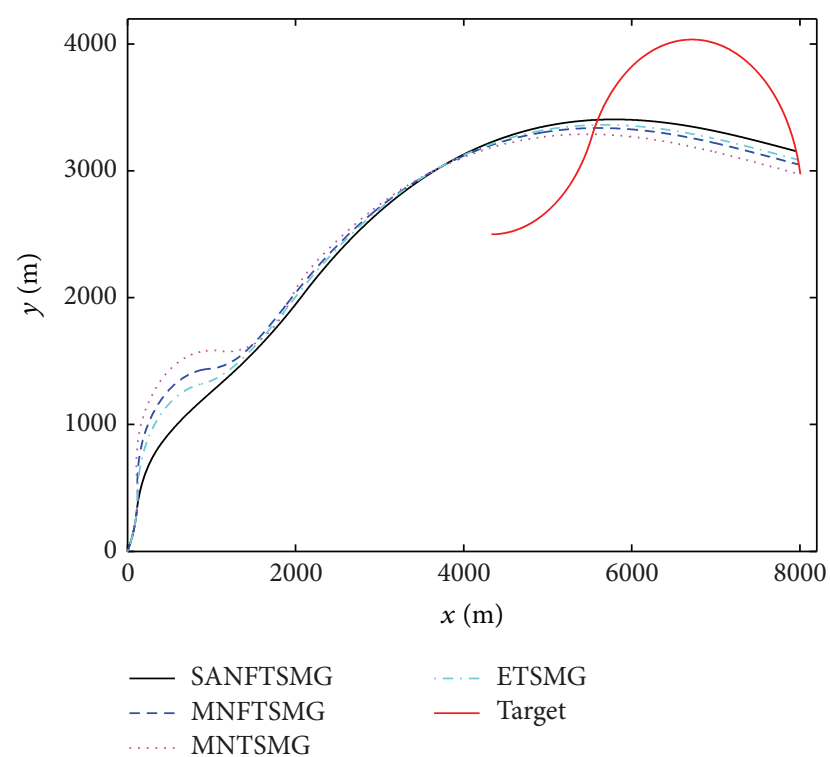

Figure 23: Trajectories of missile and target (Case 2).

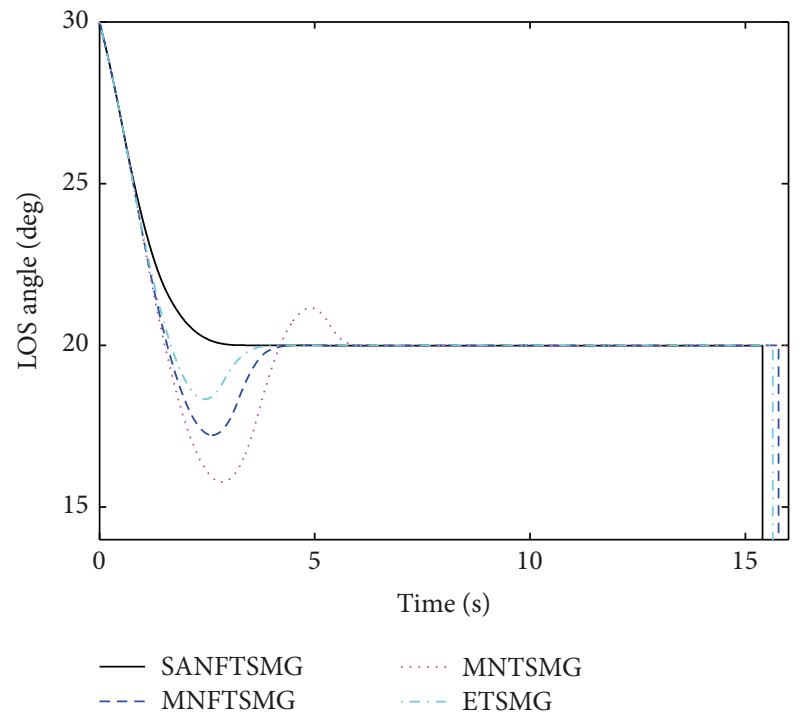

Figure 24: LOS angle (Case 2).

5.2. Simulation of SANFTSMG, MNFTSMG, and MNTSMG. To overcome the shortcoming of chattering due to the discontinuous signum function $\operatorname{sign}(s)$, the NFTSMG and NTSMG are modified by using continuous sigmoid function and saturation function, respectively. In this section, the simulations are carried out for the target acceleration profiles of Case 1 to Case 3 for comparison of the effectiveness of the SANFTSMG, MNFTSMG, MNTSMG, and ETSMG. The initial condition and the desired terminal LOS angle are the same as previous section; the simulation results are shown in Figures 18-32 and Tables 5-7, respectively.

For Case 1, it can be seen from Figure 18 and Table 5 that under the proposed SANGTSMG the trajectory of the missile is most gentle; thus the missile intercepts the target earliest $(1.068 \mathrm{~s}, 1.8740 \mathrm{~s}$, and $1.0360 \mathrm{~s}$ in advance compared with

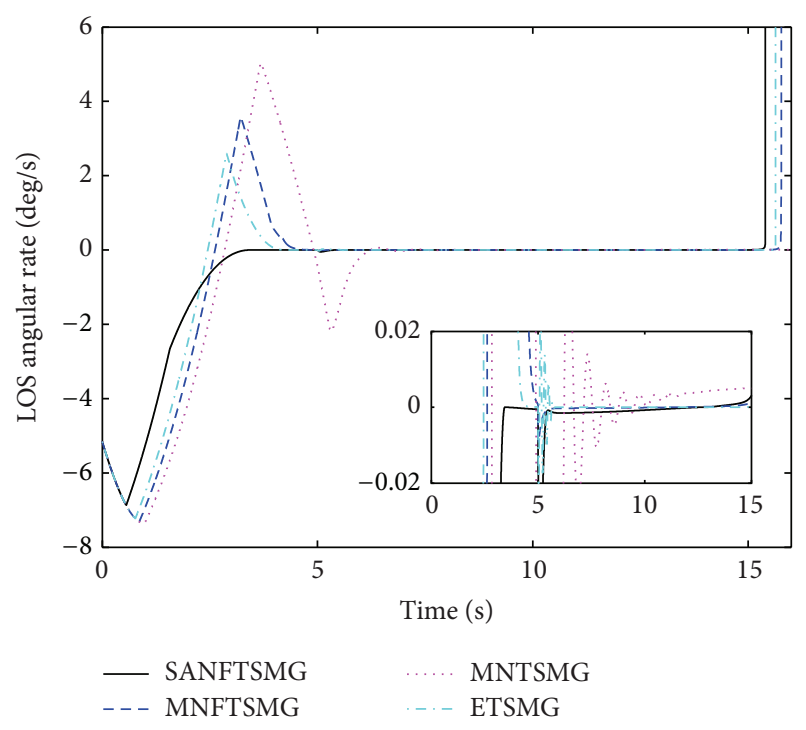

Figure 25: LOS angular rate (Case 2).

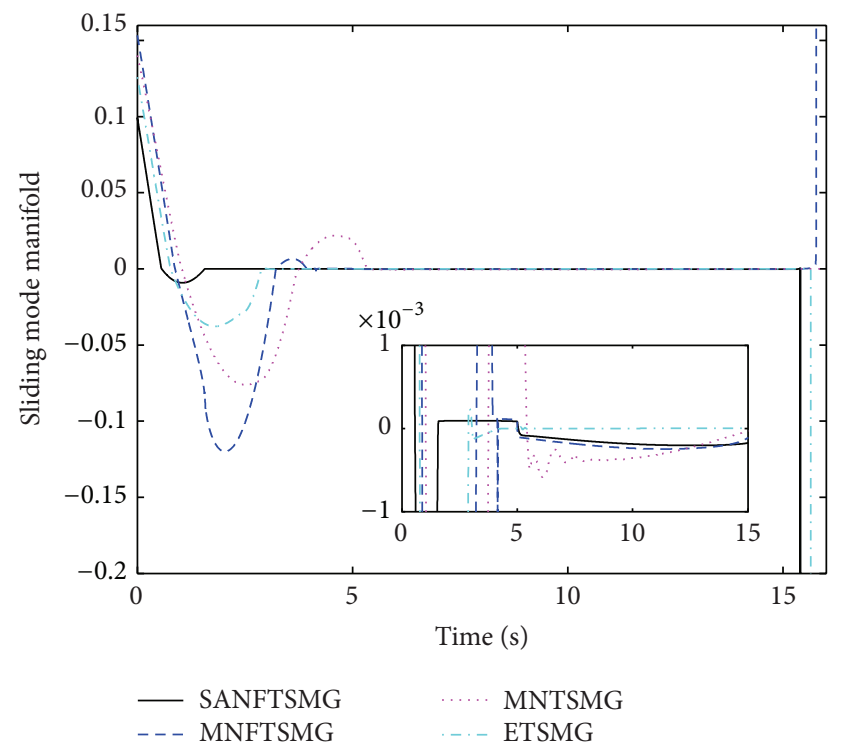

FIGURE 26: Sliding mode manifold (Case 2).

TABLE 5: Summary of simulation results in Case 1.

\begin{tabular}{lcccc}
\hline $\begin{array}{l}\text { Guidance } \\
\text { law }\end{array}$ & $\begin{array}{c}\text { Interception } \\
\text { time }(\mathrm{s})\end{array}$ & $\begin{array}{c}\text { Miss } \\
\text { distance } \\
(\mathrm{m})\end{array}$ & $\begin{array}{c}\text { LOS angel } \\
\left({ }^{\circ}\right)\end{array}$ & AAA $\left(\mathrm{m} / \mathrm{s}^{2}\right)$ \\
\hline SANFTSMG & 16.697 & 0.112 & 20.146 & 89.8900 \\
NFTSMG & 17.765 & 0.108 & 20.119 & 129.0139 \\
NTSMG & 18.571 & 0.065 & 19.913 & 158.7946 \\
ETSMG & 17.733 & 0.095 & 19.988 & 117.3914 \\
\hline
\end{tabular}

the MNFTSMG, MNTSMG, and ETSMG, resp.). Figure 19 indicates that for all of the four guidance laws the LOS angle 

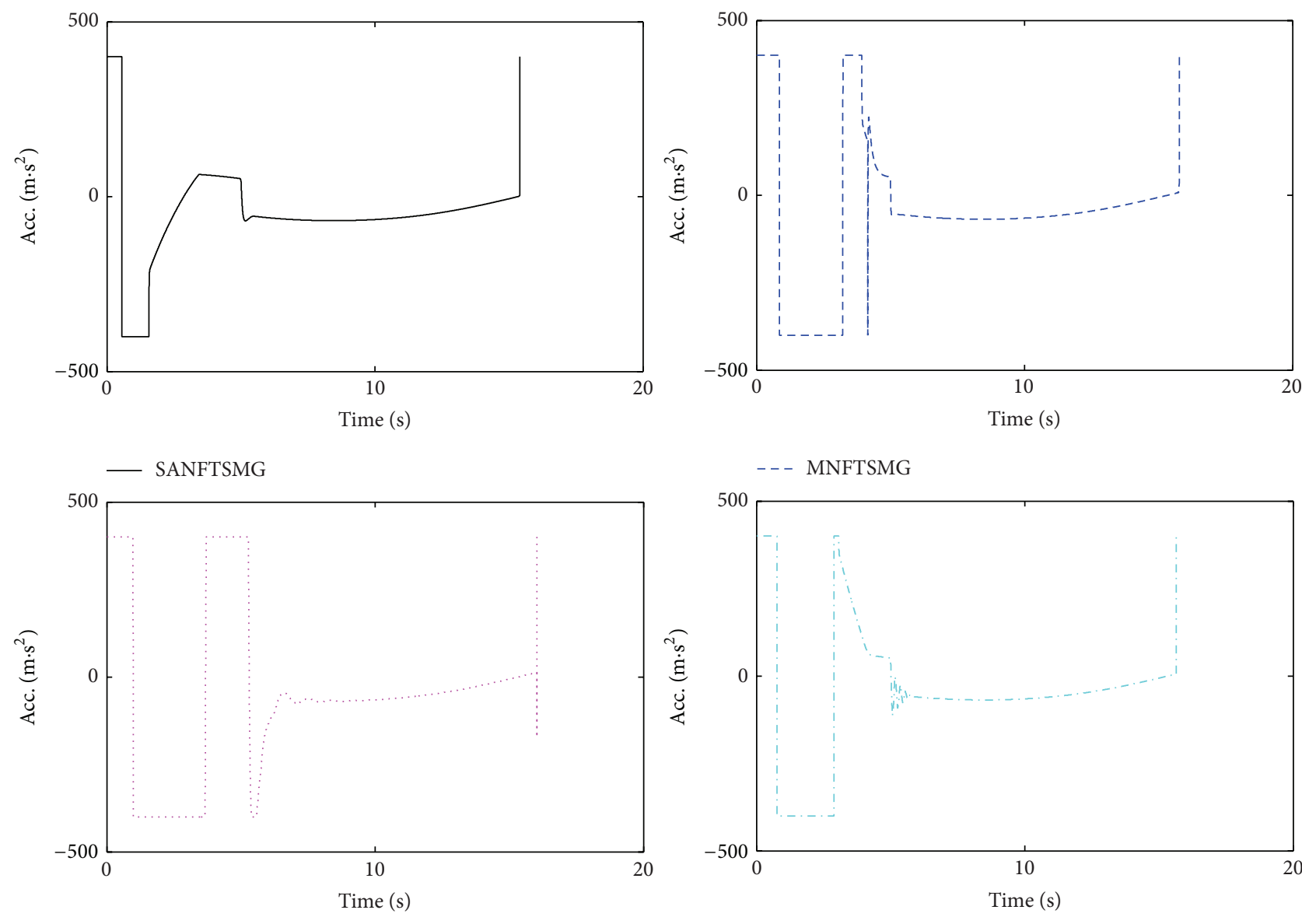

MNTSMG

- ETSMG

Figure 27: Trajectories of missile and target (Case 2).

TABLE 6: Summary of simulation results in Case 2.

\begin{tabular}{lcccc}
\hline $\begin{array}{l}\text { Guidance } \\
\text { law }\end{array}$ & $\begin{array}{c}\text { Interception } \\
\text { time }(\mathrm{s})\end{array}$ & $\begin{array}{c}\text { Miss } \\
\text { distance } \\
(\mathrm{m})\end{array}$ & $\begin{array}{c}\text { LOS angel } \\
\left({ }^{\circ}\right)\end{array}$ & AAA $\left(\mathrm{m} / \mathrm{s}^{2}\right)$ \\
\hline SANFTSMG & 15.403 & 0.007 & 19.997 & 90.8752 \\
NFTSMG & 15.770 & 0.038 & 20.014 & 140.8357 \\
NTSMG & 16.030 & 0.257 & 20.008 & 174.5899 \\
ETSMG & 15.639 & 0.192 & 20.001 & 129.5165 \\
\hline
\end{tabular}

TABLE 7: Summary of simulation results in Case 3.

\begin{tabular}{lcccc}
\hline $\begin{array}{l}\text { Guidance } \\
\text { law }\end{array}$ & $\begin{array}{c}\text { Interception } \\
\text { time }(\mathrm{s})\end{array}$ & $\begin{array}{c}\text { Miss } \\
\text { distance } \\
(\mathrm{m})\end{array}$ & $\begin{array}{c}\text { LOS angel } \\
\left(^{\circ}\right)\end{array}$ & AAA $\left(\mathrm{m} / \mathrm{s}^{2}\right)$ \\
\hline SANFTSMG & 11.840 & 0.012 & 19.798 & 89.6342 \\
NFTSMG & 12.092 & 0.033 & 19.890 & 156.7057 \\
NTSMG & 12.281 & 0.183 & 19.977 & 196.9550 \\
ETSMG & 12.001 & 0.128 & 19.988 & 141.0386 \\
\hline
\end{tabular}

can converge to the desired impact angle in finite time, and by contrast the convergent speed of SANFTSMG is the fastest.
As shown in Figures 20 and 21, the chattering of the LOS angular rate and the sliding manifold is eliminated under the MNFTSMG and MNTSMG; however the curves of the LOS angular under the NFTSMG, NTSMG, and ETSMG still have peaks near the fifth second which leads to much serious saturation compared with the SANFTSMG; as a result, the average absolute acceleration of the MNFTSMG, MNTSMG, and ETSMG is still bigger than the SANFTSMG. In addition, Figure 22 indicates that the guidance command $a_{m}$ under the MNFTSMG is still nonsmooth. That is to say, compared with the MNFTSMG, MNTSMG, and ETSMG, the SANFTSMG can still ensure that the missile can intercept the target earliest using the least actuator energy and obtain the smallest miss distance. The same conclusion can be found in the simulation results in Case 2 and Case 3, which are shown in Figures 2332 and Tables 6 and 7, respectively.

5.3. Simulation with Different Initial Flight Path Angles. The previous simulations are carried out only for a specific desired terminal LOS angel $\left(20^{\circ}\right)$ as well as the same initial flight path angle as shown in Table 1 . In order to validate the proposed SANFTSMG, in this section simulations based on the same 


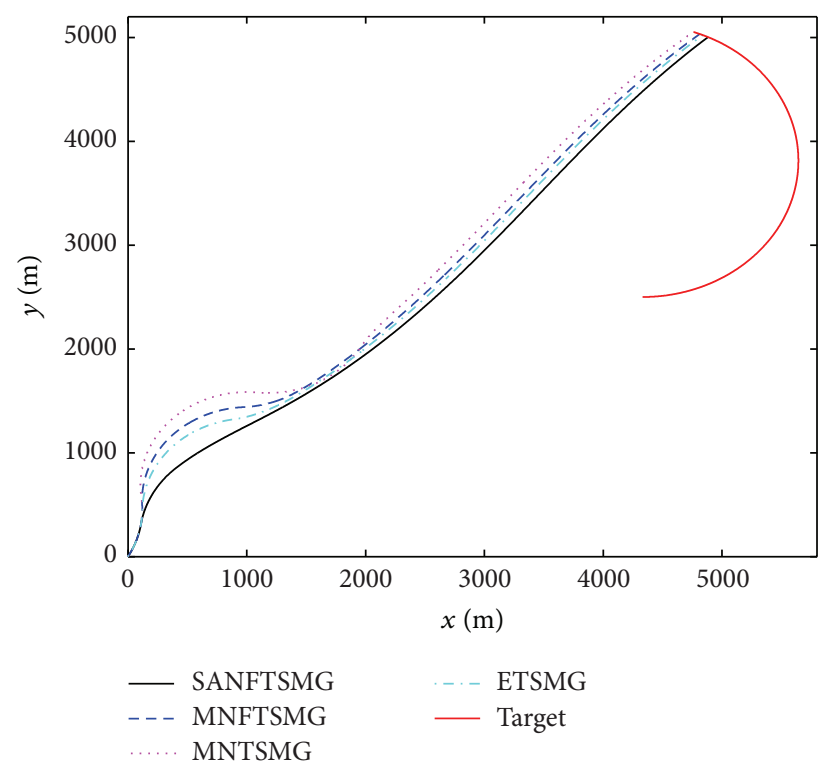

FIGURE 28: Trajectories of missile and target (Case 3).

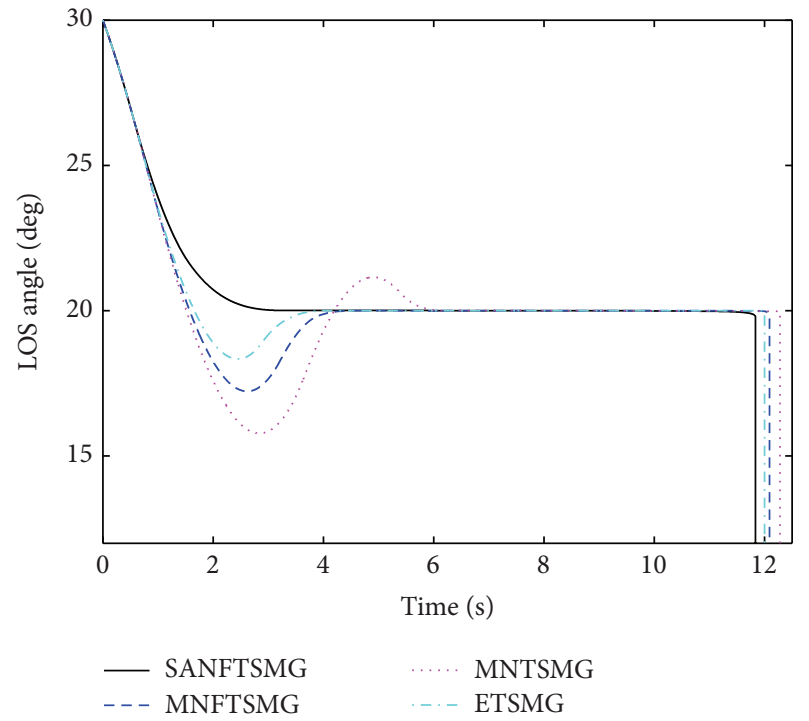

FIGURE 29: LOS angle (Case 3).

desired LOS angle and different initial flight path angles are carried out.

The desired LOS angle is selected as $20^{\circ}$, and let the initial flight path angle of the missile be $40^{\circ}, 60^{\circ}$, and $80^{\circ}$, respectively. The target acceleration is chosen as Case 2 and the other initial simulation parameters remain the same as previous simulations. With the implementation of SANFTSMG, the trajectories of missile and target, the LOS angle, the sliding manifold, and the missile acceleration are given in Figures 33-36; the miss distance, finial LOS angle, and the average absolute acceleration are summarized in Table 8 .

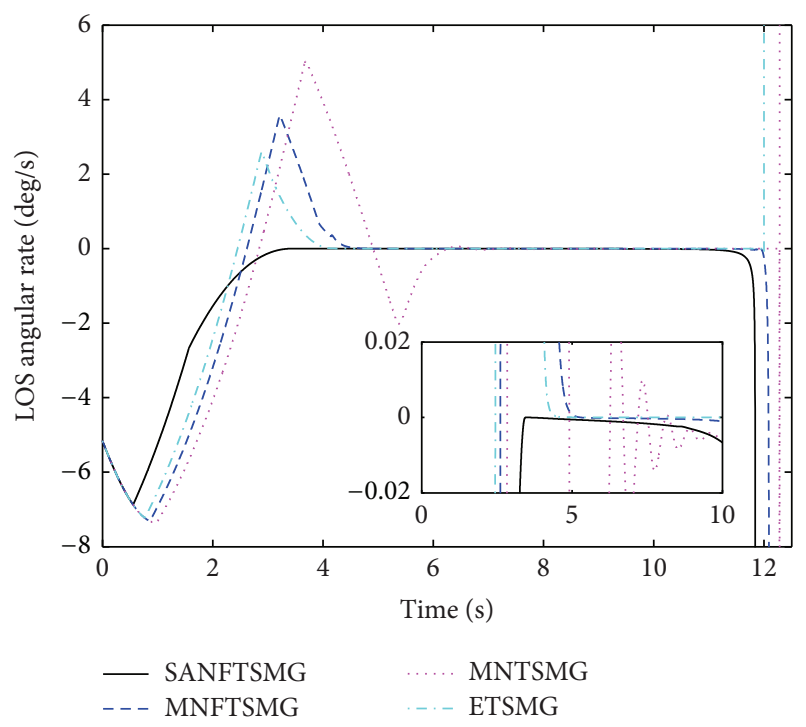

Figure 30: LOS angular rate (Case 3).

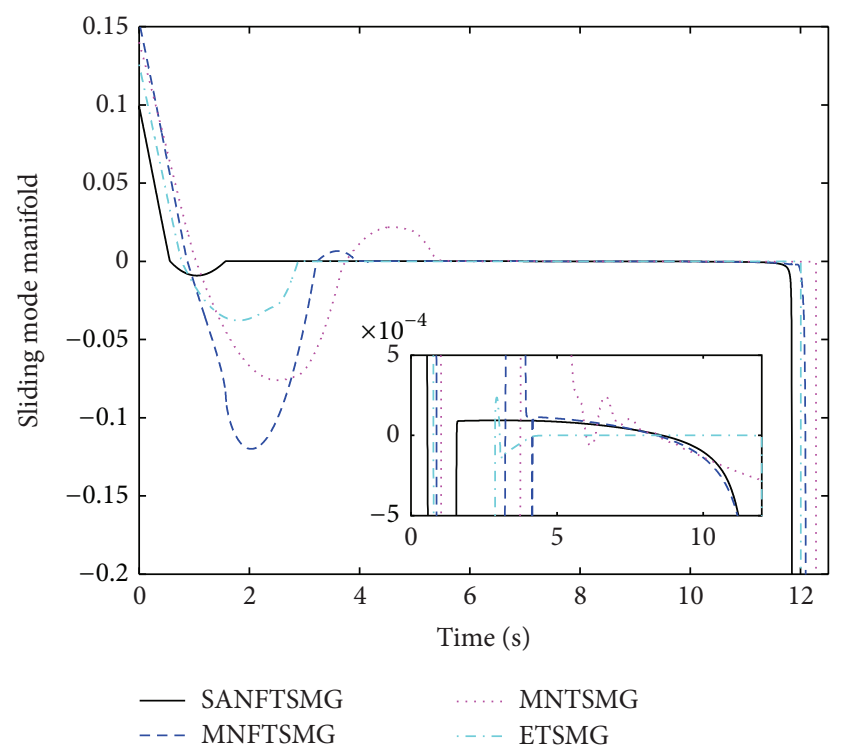

FIGURE 31: Sliding mode manifold (Case 3).

TABLE 8: Summary of simulation results with different initial flight path angles.

\begin{tabular}{lcccc}
\hline $\begin{array}{l}\text { Initial flight } \\
\text { path angle }\left({ }^{\circ}\right)\end{array}$ & $\begin{array}{c}\text { Interception } \\
\text { time }(\mathrm{s})\end{array}$ & $\begin{array}{c}\text { Miss } \\
\text { distance } \\
(\mathrm{m})\end{array}$ & $\begin{array}{c}\text { LOS angle } \\
\left({ }^{\circ}\right)\end{array}$ & AAA $\left(\mathrm{m} / \mathrm{s}^{2}\right)$ \\
\hline 40 & 15.316 & 0.152 & 19.989 & 93.6704 \\
60 & 15.403 & 0.007 & 19.997 & 90.8752 \\
80 & 15.553 & 0.082 & 20.009 & 97.5046 \\
\hline
\end{tabular}

From Figure 33, it can be seen that the missile can intercept precisely the target from different initial flight path angles with impact angle constraint. Figures 34 and 35 show 

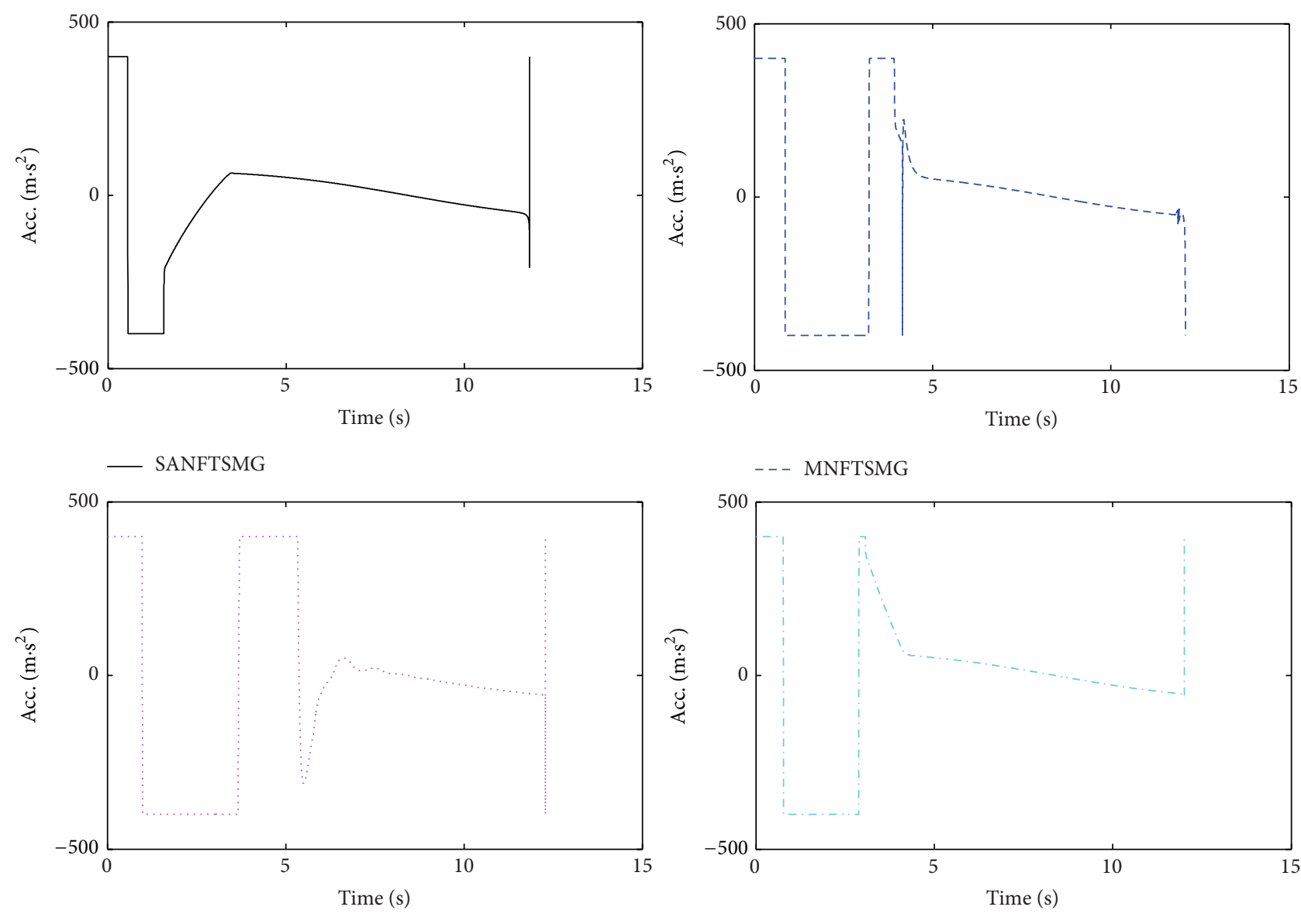

MNTSMG

ETSMG

Figure 32: Trajectories of missile and target (Case 3).

TABle 9: Summary of simulation results with different impact angles.

\begin{tabular}{lcccc}
\hline $\begin{array}{l}\text { Desired LOS } \\
\text { angle }\left({ }^{\circ}\right)\end{array}$ & $\begin{array}{c}\text { Interception } \\
\text { time }(\mathrm{s})\end{array}$ & $\begin{array}{c}\text { Miss } \\
\text { distance } \\
(\mathrm{m})\end{array}$ & $\begin{array}{c}\text { LOS angle } \\
\left({ }^{\circ}\right)\end{array}$ & AAA $\left(\mathrm{m} / \mathrm{s}^{2}\right)$ \\
\hline 20 & 15.332 & 0.225 & 19.990 & 92.2791 \\
30 & 14.759 & 0.092 & 30.012 & 89.2257 \\
40 & 15.317 & 0.002 & 40.041 & 169.7103 \\
\hline
\end{tabular}

that the LOS angle and the sliding manifold can converge to $20^{\circ}$ and zero in finite time, respectively. The missile acceleration command in Figure 36 is within the reasonable bound. From Table 8, it can be observed that the miss distance and terminal LOS angle error are satisfactory and the average absolute acceleration is relatively small. By contrast, when the initial flight path angle is selected as $40^{\circ}$, the missile intercepts the target earliest, while $60^{\circ}$ produces the least average absolute acceleration.
5.4. Simulation with Different Desired LOS Angles. The final simulations for different desired LOS angles but from the same initial flight path angle are performed in this section. The initial flight path angle is selected as $45^{\circ}$, and let the desired LOS angle of the missile be $20^{\circ}, 30^{\circ}$, and $40^{\circ}$, respectively. The target acceleration is chosen as Case 2 and the other initial simulation parameters remain the same as previous simulations. The simulation results are shown in Figures 37-40 and Table 9, respectively.

From Figure 37, it can be seen that the missile can intercept precisely the target with different impact angle constraint from the same initial flight path angle. Figure 38 shows that the LOS angle can converge to $20^{\circ}, 30^{\circ}$, and $40^{\circ}$ in finite time, respectively, and the terminal LOS angle error is less than $0.05^{\circ}$ which is reflected in the fourth column of Table 9. The sliding manifolds are shown in Figure 39, which indicate that system state of (12) converges to zero in finite time with all the three desired LOS angles, and by contrast when the desired LOS angle is selected as $40^{\circ}$, the convergent speed is the slowest; this can be found from the trajectory of missile in Figure 37 and the LOS angle curve in Figure 38. In addition, Table 9 shows that the simulation for the desired LOS angles of $40^{\circ}$ needs the biggest average absolute acceleration. 


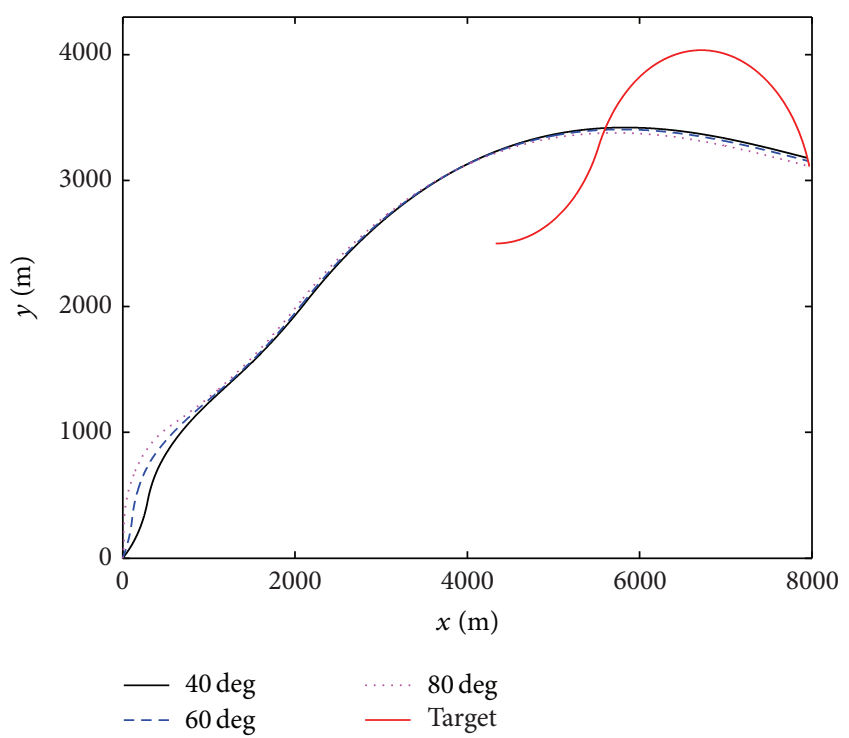

Figure 33: Trajectories of missile and target.

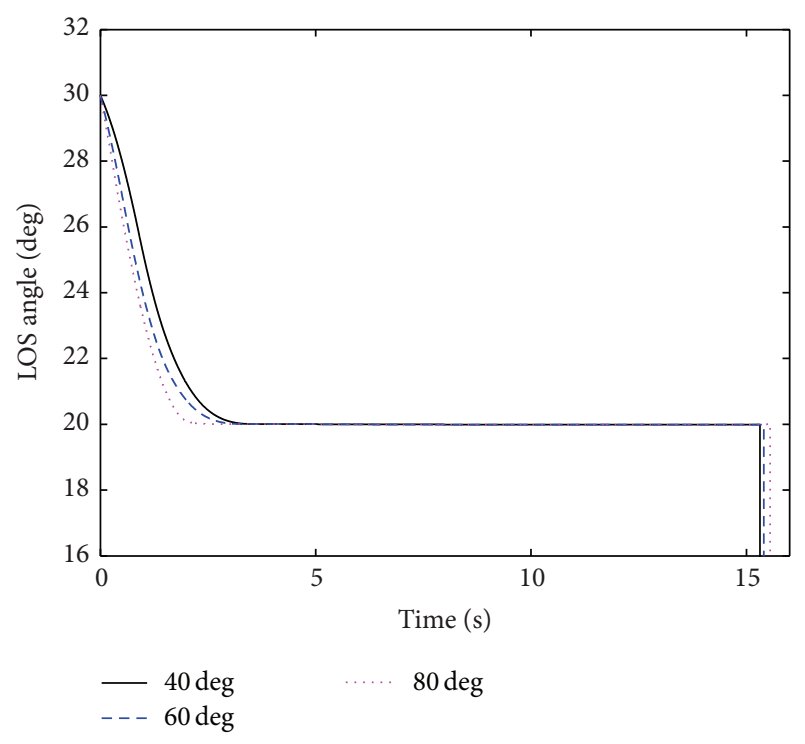

FIGURE 34: LOS angle.

By contrast, when the initial flight path angle is selected as $30^{\circ}$, the missile intercepts the target earliest and it produces the least average absolute acceleration.

\section{Conclusion}

In this paper, we have proposed a new smooth adaptive nonsingular fast terminal sliding mode guidance law considering the terminal angle constraint for intercepting the maneuvering targets on the nonsingular fast terminal sliding mode control scheme and adaptive control scheme. Different from the existing adaptive law for estimating the upper bound

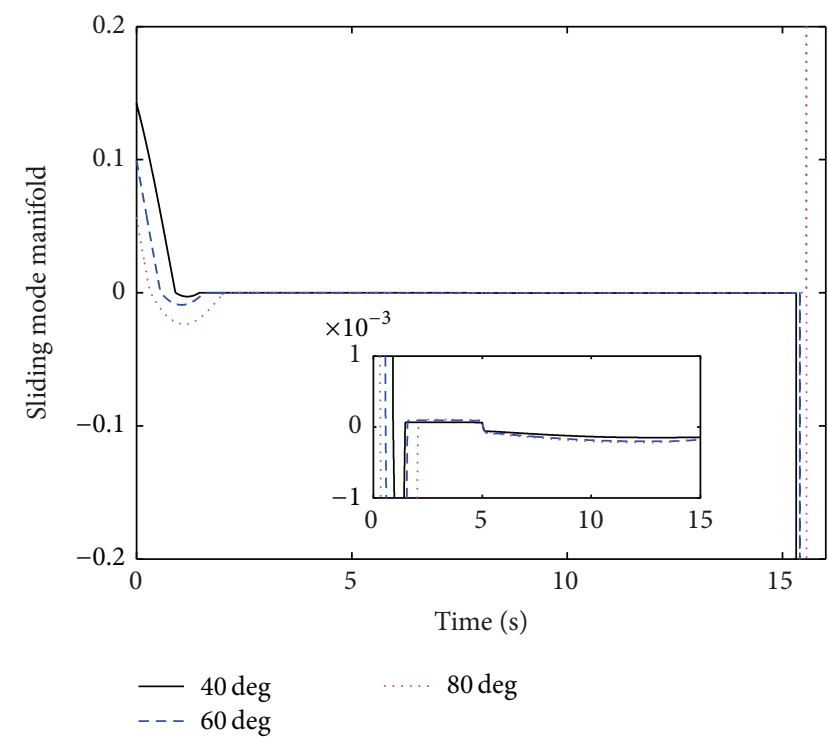

FIGURE 35: Sliding mode manifold.
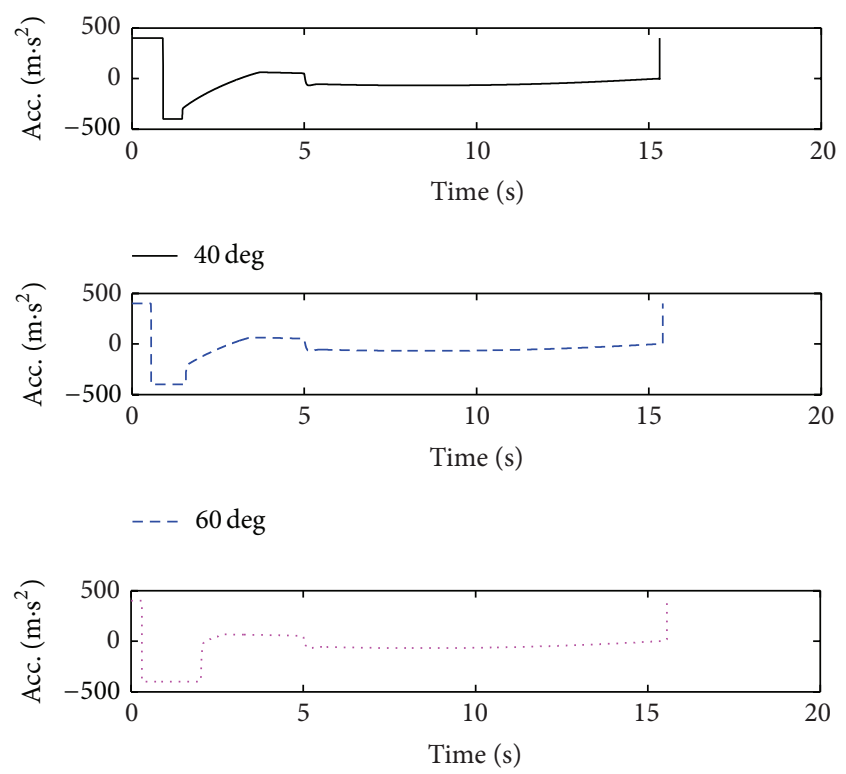

$80 \mathrm{deg}$

Figure 36: Missile acceleration.

of the system uncertainty, the adaptive law employed in SANFTSMG is designed to estimate the square of the upper bound of the target maneuvering; in this way, not only is the prior information of the target maneuvering unnecessary, but also the nonsmooth signum function existing in the traditional sliding mode guidance laws is eliminated, which ensures the smooth property of the guidance law. On the other hand, due to the usage of the nonsingular fast terminal sliding manifold, the SANFTSMG is nonsingular. Furthermore, the precise convergent region of the sliding manifold, the LOS, and the LOS angular rate are given based on Lyapunov method and 


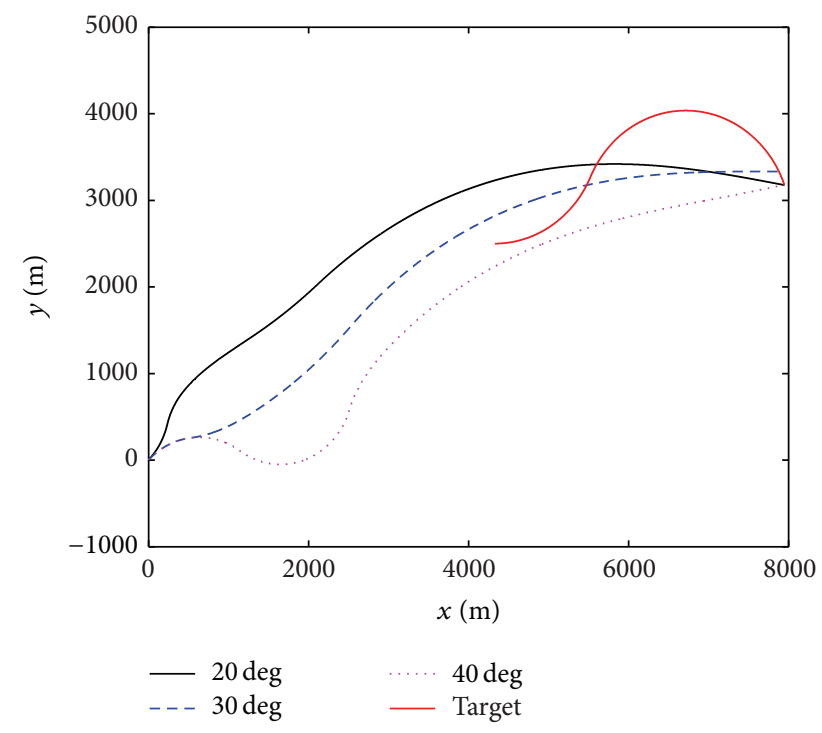

Figure 37: Trajectories of missile and target.

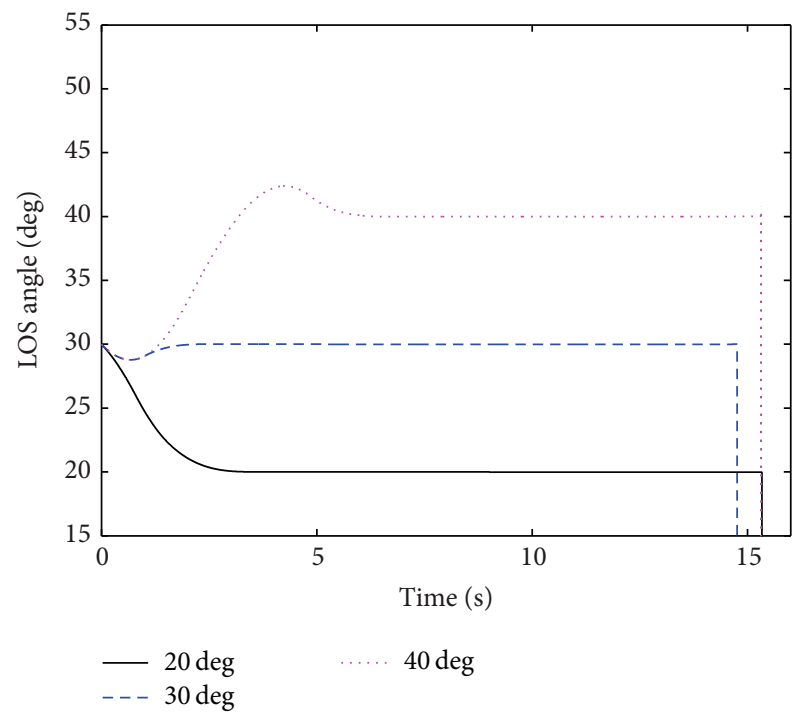

FIGURE 38: LOS angle.

finite time theory. It can be indicated from the simulation results of different scenarios that with the described guidance law the finite time convergence of the guidance system is guaranteed, and compared with similar guidance law [29, 32], under the SANFTSMG, the missile can intercept the target earliest using the least actuator energy and obtain the smallest miss distance, which shows the superiority of this method.

\section{Competing Interests}

The authors declare that there are no competing interests regarding the publication of this paper.

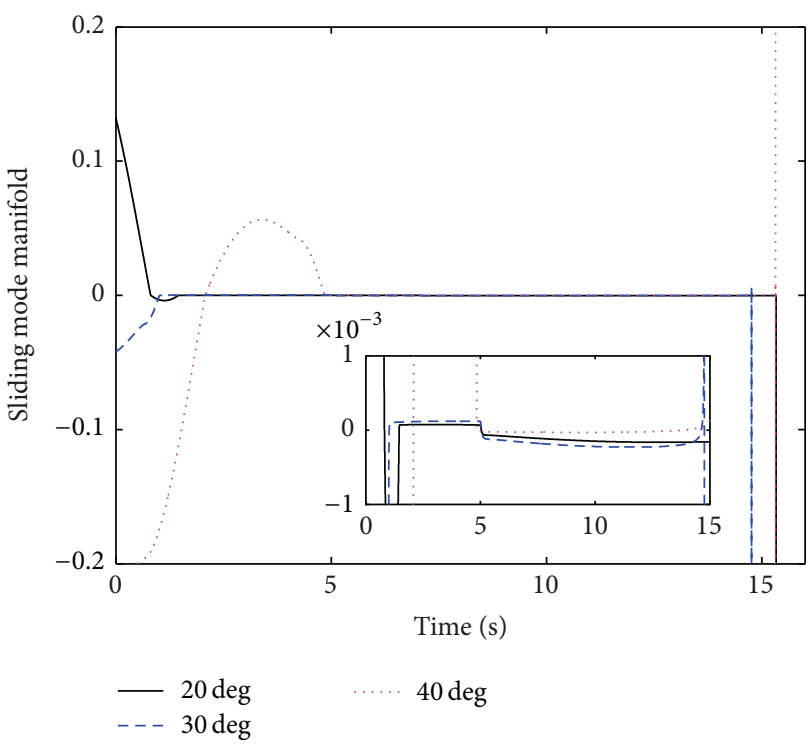

Figure 39: Sliding mode manifold.
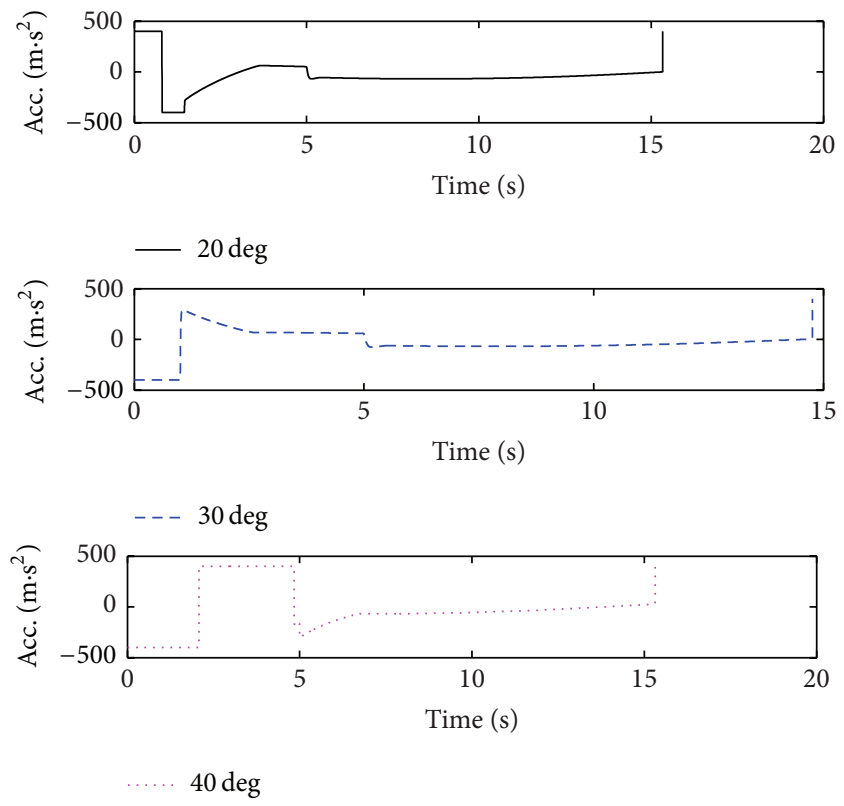

Figure 40: Missile acceleration.

\section{Acknowledgments}

The work is supported by the National High-Tech R\&D Program of China under Grants 2015AAXXX7033 and 2015AAXXX1008 and the Chinese Aerospace Supported Fund (2015-HT-XGD).

\section{References}

[1] S. R. Kumar, S. Rao, and D. Ghose, "Sliding-mode guidance and control for all-aspect interceptors with terminal angle constraints," Journal of Guidance, Control, and Dynamics, vol. 35, no. 4, pp. 1230-1246, 2012. 
[2] S. A. Murtaugh and H. E. Criel, "Fundamentals of proportional navigation," IEEE Spectrum, vol. 3, no. 12, pp. 75-85, 1966.

[3] M. Guelman, "A qualitative study of proportional navigation," IEEE Transactions on Aerospace and Electronic Systems, vol. 7, no. 4, pp. 637-643, 1971.

[4] M. Guelman, "Proportional navigation with a maneuvering target," IEEE Transactions on Aerospace and Electronic Systems, vol. 8, no. 3, pp. 364-371, 1972.

[5] P.-J. Yuan and J.-S. Chern, "Ideal proportional navigation," Journal of Guidance, Control, and Dynamics, vol. 15, no. 5, pp. 1161-1165, 1992.

[6] B. S. Kim, J. G. Lee, and H. S. Han, "Biased PNG law for impact with angular constraint," IEEE Transactions on Aerospace and Electronic Systems, vol. 34, no. 1, pp. 277-288, 1998.

[7] K. S. Erer and O. Merttopçuoglu, "Indirect impact-anglecontrol against stationary targets using biased pure proportional navigation," Journal of Guidance, Control, and Dynamics, vol. 35, no. 2, pp. 700-704, 2012.

[8] A. Ratnoo and D. Ghose, "Impact angle constrained interception of stationary targets," Journal of Guidance, Control, and Dynamics, vol. 31, no. 6, pp. 1816-1821, 2008.

[9] A. Ratnoo and D. Ghose, "Impact angle constrained guidance against nonstationary nonmaneuvering targets," Journal of Guidance, Control, and Dynamics, vol. 33, no. 1, pp. 269-275, 2010.

[10] P. Zarchan, Tactical and Strategic Missile Guidance, American Institute of Aeronautics and Astronautic, New York, NY, USA, 1998.

[11] M. Kim and K. V. Grider, "Terminal guidance for impact attitude angle constraints flight trajectories," IEEE Transactions on Aerospace and Electronic Systems, vol. 9, no. 6, pp. 852-859, 1973.

[12] T. L. Song, S. J. Shin, and H. Cho, "Impact angle control for planar engagements," IEEE Transactions on Aerospace and Electronic Systems, vol. 35, no. 4, pp. 1439-1444, 1999.

[13] C.-K. Ryoo, H. Cho, and M.-J. Tahk, “Time-to-go weighted optimal guidance with impact angle constraints," IEEE Transactions on Control Systems Technology, vol. 14, no. 3, pp. 483-492, 2006.

[14] H. Y. Chen and C. D. Yang, "Nonlinear $H_{\infty}$ robust guidance law for homing missiles," Tech. Rep. AIAA-98-4212, 1998.

[15] C. D. Yang and H. Y. Chen, "Three-dimensional nonlinear $H_{\infty}$ guidance law," International Journal of Robust Nonlinear Control, vol. 21, no. 3, pp. 109-129, 2001.

[16] V. I. Utkin, "Variable structure systems with sliding modes," IEEE Transactions on Automatic Control, vol. 21, no. 2, pp. 212222, 1977.

[17] S. D. Brierley and R. Longchamp, "Application of sliding-mode control to air-air interception problem," IEEE Transactions on Aerospace and Electronic Systems, vol. 26, no. 2, pp. 306-325, 1990.

[18] N. Harl and S. N. Balakrishnan, "Impact time and angle guidance with sliding mode control," IEEE Transactions on Control Systems Technology, vol. 20, no. 6, pp. 1436-1449, 2012.

[19] Z. Man, A. P. Paplinski, and H. R. Wu, "A robust MIMO terminal sliding mode control scheme for rigid robotic manipulators," IEEE Transactions on Automatic Control, vol. 39, no. 12, pp. 2464-2469, 1994.

[20] Z. Man and X. H. Yu, "Terminal sliding mode control of MIMO linear systems," in Proceedings of the IEEE Conference on Decision and Control, pp. 4619-4624, Piscataway, NJ, USA, 1996.
[21] S. He and D. Lin, "A robust impact angle constraint guidance law with seeker's field-of-view limit," Transactions of the Institute of Measurement and Control, vol. 37, no. 3, pp. 317-328, 2015.

[22] Y. X. Zhang, M. W. Sun, and Z. Q. Chen, "Finite-time convergent guidance law with impact angle constraint based on sliding-mode control," Nonlinear Dynamics, vol. 70, no. 1, pp. 619-625, 2012.

[23] X. H. Yu and M. Zhihong, "Fast terminal sliding-mode control design for nonlinear dynamical systems," IEEE Transactions on Circuits and Systems. I. Fundamental Theory and Applications, vol. 49, no. 2, pp. 261-264, 2002.

[24] M. Golestani, A. R. Vali, S. Najjari, and I. Mohammadzaman, "Finite-time convergence of guidance system via fast terminal sliding mode control," in Proceedings of the 23rd Iranian Conference on Electrical Engineering (ICEE '15), pp. 899-904, Tehran, Iran, May 2015.

[25] J. Song, S. Song, Y. Guo, and H. Zhou, "Nonlinear disturbance observer-based fast terminal sliding mode guidance law with impact angle constraints," International Journal of Innovative Computing, Information and Control, vol. 11, no. 3, pp. 787-802, 2015.

[26] Y. Feng, X. Yu, and Z. Man, "Non-singular terminal sliding mode control of rigid manipulators," Automatica, vol. 38, no. 12, pp. 2159-2167, 2002.

[27] S. Yu, X. Yu, B. Shirinzadeh, and Z. Man, "Continuous finitetime control for robotic manipulators with terminal sliding mode," Automatica, vol. 41, no. 11, pp. 1957-1964, 2005.

[28] L. Yang and J. Yang, "Nonsingular fast terminal sliding-mode control for nonlinear dynamical systems," International Journal of Robust and Nonlinear Control, vol. 21, no. 16, pp. 1865-1879, 2011.

[29] J. H. Song, M. S. Song, and H. B. Zhou, "Adaptive nonsingular fast terminal sliding mode guidance law with impact angle constraints," International Journal of Control, Automation and Systems, vol. 14, no. 1, pp. 99-114, 2016.

[30] S. He, D. Lin, and J. Wang, "Robust terminal angle constraint guidance law with autopilot lag for intercepting maneuvering targets," Nonlinear Dynamics, vol. 81, no. 1, pp. 881-892, 2015.

[31] S. R. Kumar, S. Rao, and D. Ghose, "Nonsingular terminal sliding mode guidance with impact angle constraints," Journal of Guidance, Control, and Dynamics, vol. 37, no. 4, pp. 1114-1130, 2014.

[32] S. M. He and D. F. Lin, "Adaptive nonsingular sliding mode based guidance law with terminal angular constraint," International Journal of Aeronautical and Space Sciences, vol. 15, no. 2, pp. 146-152, 2014.

[33] S. Xiong, W. Wang, S. Song, S. Wang, and C. Lai, "Extended state observer based impact angle constrained guidance law for maneuvering target interception," Proceedings of the Institution of Mechanical Engineers, Part G: Journal of Aerospace Engineering, vol. 229, no. 14, pp. 2589-2607, 2015.

[34] W. Wang, S. Xiong, X. Liu, S. Wang, and L. Ma, "Adaptive nonsingular terminal sliding mode guidance law against maneuvering targets with impact angle constraint," Proceedings of the Institution of Mechanical Engineers, Part G, vol. 229, no. 5, pp. 867-890, 2015.

[35] C. Sun and C.-B. Feng, "Exponential periodicity and stability of delayed neural networks," Mathematics and Computers in Simulation, vol. 66, no. 6, pp. 469-478, 2004. 


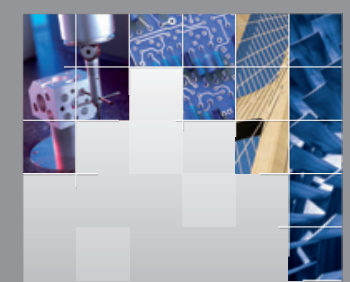

\section{Enfincering}
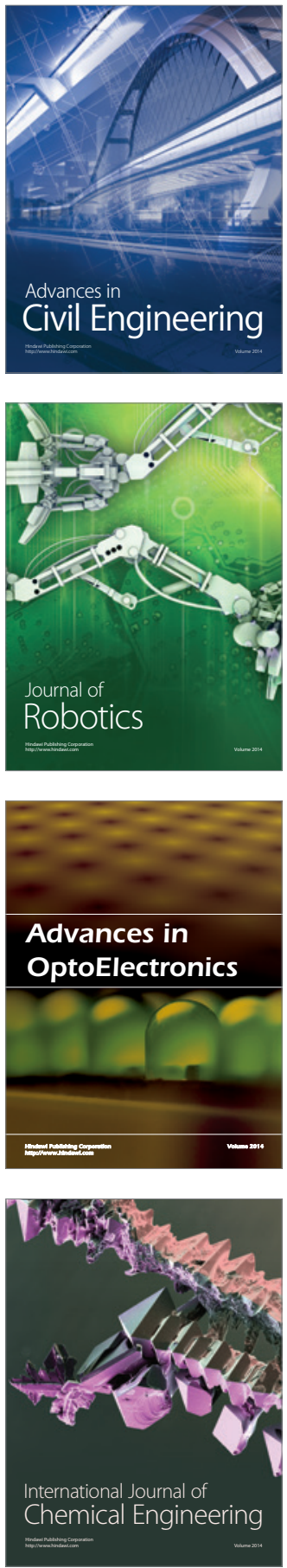

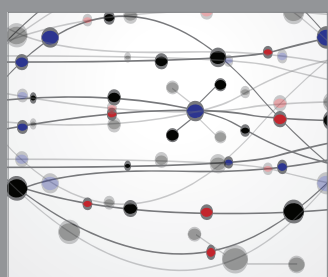

The Scientific World Journal

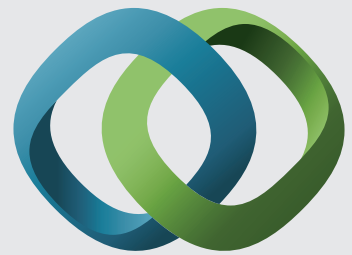

\section{Hindawi}

Submit your manuscripts at

http://www.hindawi.com
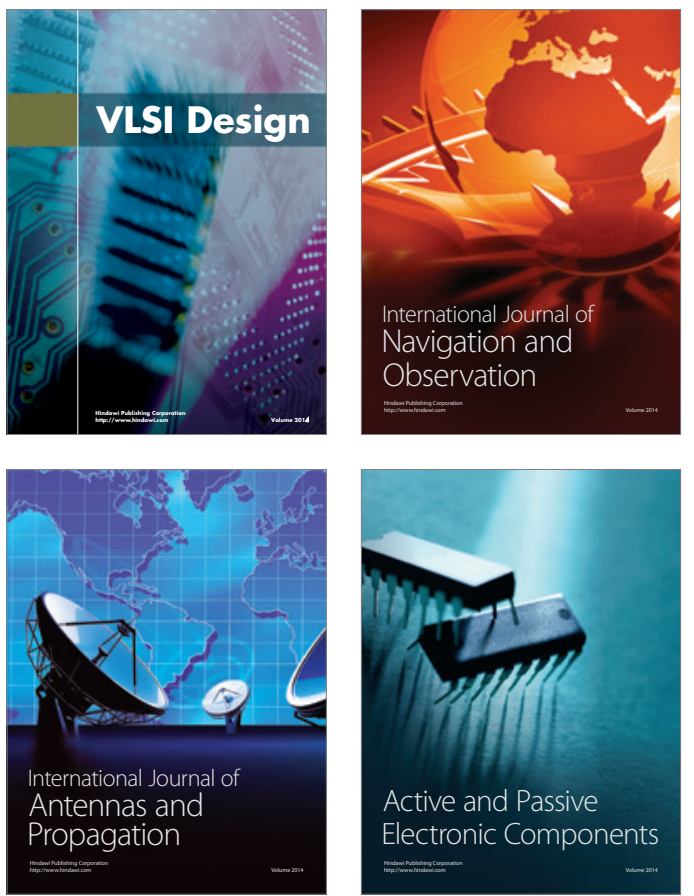
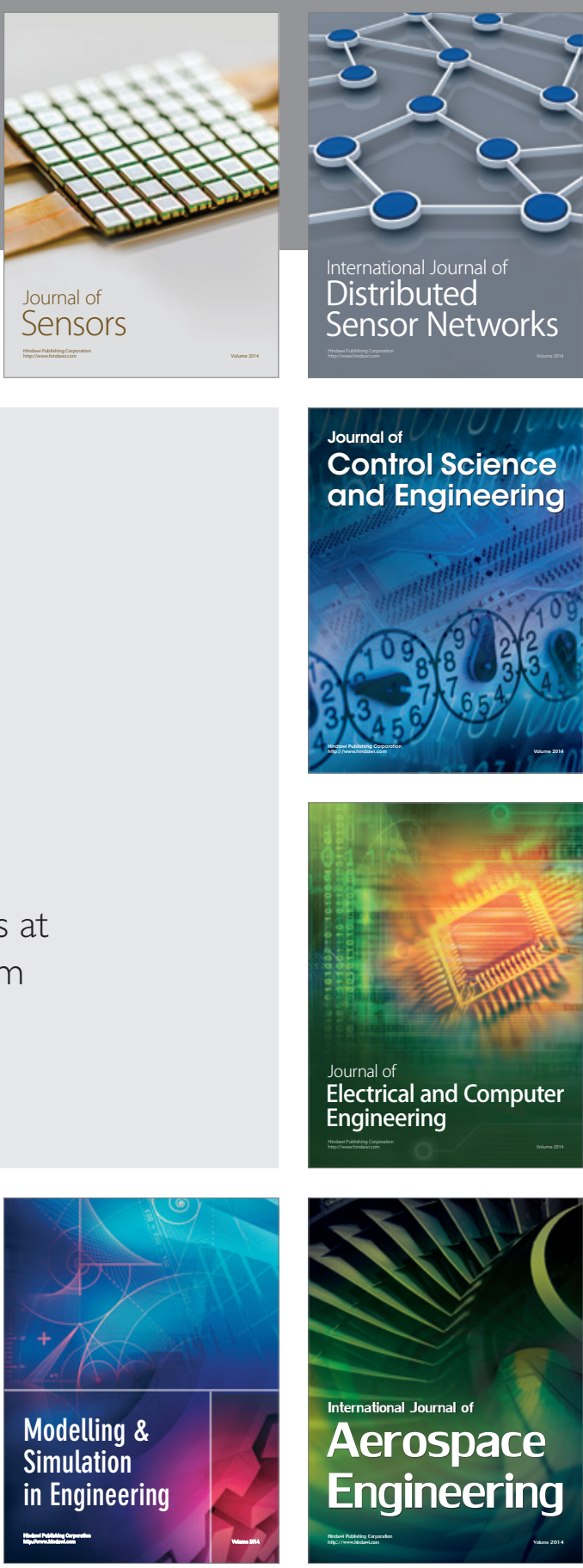

International Journal of

Distributed

Sensor Networks

Journal of

Control Science

and Engineering
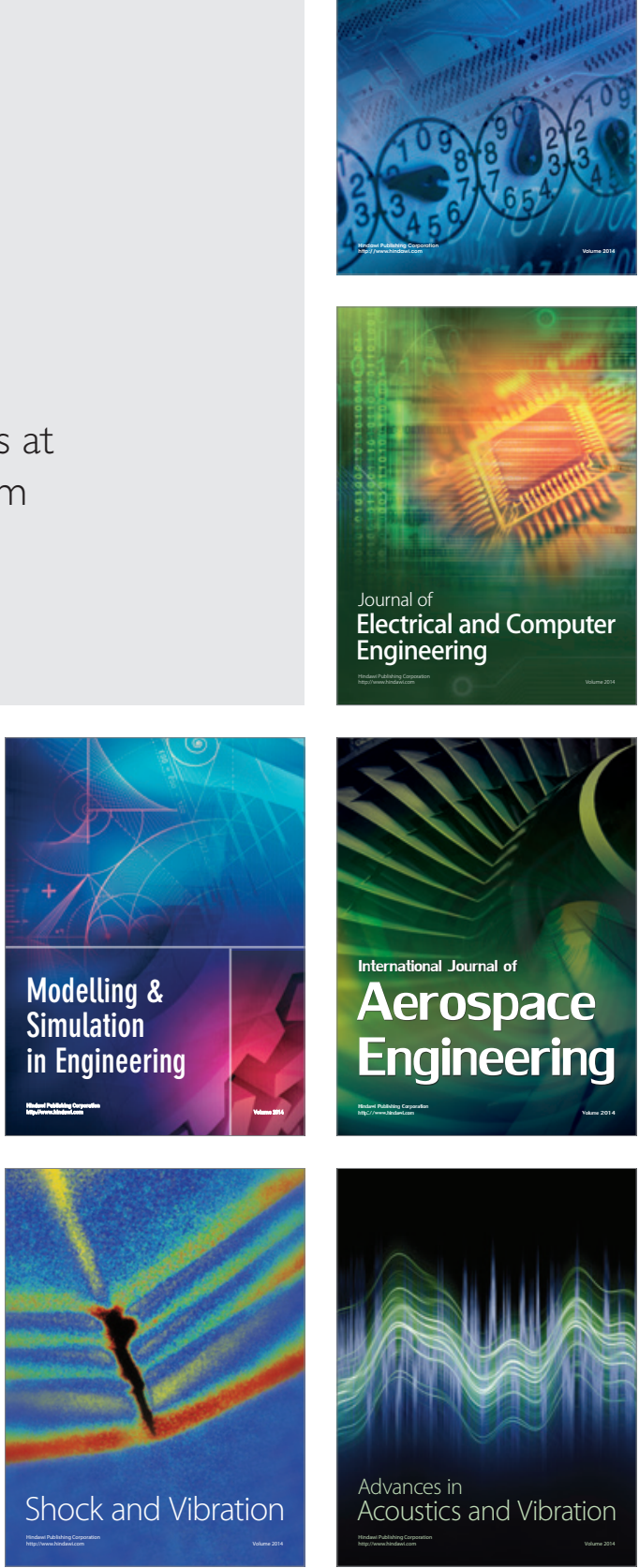